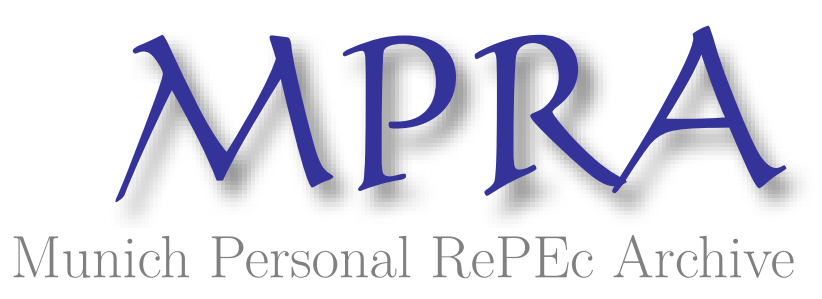

Do Stock Returns Provide a Good Hedge Against Inflation? An Empirical Assessment Using Turkish Data during Periods of Structural Change

\author{
Akturk, Halit \\ Meliksah University
}

July 2014

Online at https://mpra.ub.uni-muenchen.de/64465/

MPRA Paper No. 64465, posted 22 May 2015 13:54 UTC 


\title{
Do Stock Returns Provide a Good Hedge Against Inflation? An Empirical Assessment Using Turkish Data during Periods of Structural Change
}

\author{
Halit Aktürk \\ Department of Economics \\ Melikşah University \\ 38280 Kayseri, TURKEY
}

July 2014

\begin{abstract}
This paper provide empirical evidence on the relation between stock returns and inflationary expectations using a panel of firm level data covering a broad range of industries and Turkish common stock market index from 1986 to 2013. I use survey of inflationary expectations to examine Fisher hypothesis where I show, no matter the data is aggregate or disaggregated; ex-ante inflationary expectations and stock returns are positively related, whereas ex-post inflationary realizations are negatively related. I find that holding stocks of manufacturing industry firms provide for about $15 \%$ better hedge in comparison to that of service industry firms.
\end{abstract}




\section{Introduction}

Ceteris paribus, inflation decreases the amount of goods and services a person would be able to purchase which reduces the standard of living. Therefore, the methods to hedge against inflation are important in investment decision making. To successfully hedge against inflation and maintain a certain purchasing power in real terms, any investment must bring returns above or at least at the same rate of inflation. Stock market where savings are directly transferred to borrowers may play an important role in providing provide a hedge against inflation.

The Turkish economy experienced very high, relatively lower, and low levels of inflation in the last thirty years where inflation has always been a concern. Many failed to sustain purchasing power in real terms due to inflation partially due to not being able to utilize the stock market. In comparison to industrialized countries, Turkey has a shallow stock market with relatively limited financial instruments. Having a high level of dynamic and young working age population, Turkey need to deepen its stock market and encourage private savers to improve national savings to enhance overall productivity. Though the stock market is shallow, if stock returns can provide a hedge against inflation, this may stimulate savings by encouraging more people to participate in the stock market.

The research question of this study is on whether stock returns provide a good hedge against inflation during periods of structural change in Turkey between the periods of 1986 to 2013. During the period under investigation, the Turkish economy experienced very high, relatively lower, and low levels of inflation along with different inflation reduction programs as presented in Table 1. Using aggregate (common stock market) and disaggregate, (both company and industry level) data, I attempt to provide empirical evidence for whether stock returns provide a hedge against expected or 
unexpected inflation. Using a dataset at both aggregate and disaggregate levels gives me the opportunity to identify whether the relationship between stock returns and expected inflation change due to aggregation. Studying segments of time periods associated with different price dynamics allow me to argue on whether stock returns provide hedge in certain periods of high, moderate or low levels of inflation. Finally, using survey of expectations data and realized forward values helps me to distinguish between the impact of ex-ante, ex-post, expected and unexpected inflationary expectations on stock returns.

\section{Literature Review}

Generalized Fisher hypothesis, when applied to assets or common stocks, suggests that there is a positive relationship between nominal stock returns and expected inflation. Existing research on the relationship between stock returns and expected inflation hasn't reached a consensus yet.

There is a large literature on the negative relationship between inflation and stock returns. Comparing the performance of common stocks against inflation with that of some other financial variables in for the U.S. economy, Bodie (1976), Nelson (1976), and Fama and Schwert (1977) found that common stocks provide poor hedge against both expected and unexpected inflation. Yasser and Magda's (2003) Johansen tests for conintegration results do not support short-run Fisher effect, but at log horizons Fisher's one-to-one relation seem to hold using U.S. data. Geske and Roll (1983) show that stock returns are negatively related to both expected and unexpected inflation where this empirical phenomenon does not indicate causality. Geske and Roll (1983) proposed "reversed causality" where low stock returns are consistent with higher inflationary expectations as they signal for a drop in economic activity resulting in a higher rate of monetary expansion. Using a panel of nine countries during 1971-80, Solnik (1983) 
provides empirical evidence supporting Geske and Roll (1983) model where stock price movements signal negative inflationary expectations.

Some research provides evidence for both negative and positive relationship between inflation and stock returns using ex-ante inflationary expectations vs. ex-post realizations or evaluating different time periods. Gultekin (1983) uses Livingston survey of expectations data where he provides evidence that Fisher hypothesis holds better when ex-ante expectations vs. ex-post realizations are used in the empirical estimations. Using a structural VAR identification method Lee (2010) finds evidence both in favor and in contrast of the so-called inflation illusion hypothesis where negative relationship between inflation and stock returns is predicted. He provides evidence for the existence of negative relationship between inflation and stock returns for the post-war period and positive relationship for the pre-war period.

Does the source and the level of inflation matter for the relationship between inflation and stock returns? Ely and Robinson (1997) show that, no matter the source of inflation, stock returns maintain their value relative to CPI inflation. On the other hand, Lee et al. (2000) examine relationship between stock returns and inflation during the German hyperinflation period during which they argue that monetary and real sectors of the economy are isolated. Making a clear distinction between monetary and real sectors allow that to show the impact of inflation on stock returns directly where they find positive correlation between inflation (both expected and realized inflation) and stock returns.

Recent research using conintegration techniques or industry level data are in favor of positive relationship between inflation and stock returns. Using stock price and goods price data from six industrial countries and conintegration techniques, Kolari and Anari (2001) show that the long-run Fisher elasticities of stock prices with respect to 
goods prices are in the range of 1.04 to 1.65 , which support the Fisher effect adjusted for tax effects as described in Crowder and Hoffman (1996). Luintel and Paudyal (2006) use aggregate and disaggregate data (seven industry groups) along with conintegration methods where they find point estimates of stock price elasticities with respect to goods prices are significantly above unity.

Previous research using Turkish aggregate level data on the relationship between inflation and common stock returns have contradictory findings. İncekara et al. (2012) employ Johansen conintegration technique and VAR approach, Şimşek and Kadılar (2004) use Paseran et al.'s ARDL approach where they all find empirical evidence in favor of Fisher hypothesis in the long run. On the other hand, Turgutlu (2004) uses Engle-Granger tests, Gül and Açıkalın (2008) employs Johansen conintegration method where they find evidence contradicting the Fisher's one-to-one relationship between expected inflation and stock returns.

My research paper is distinct in many ways in comparison to the existing research on relationship between stock returns and inflation and to those papers using Turkish data. First, I conduct analysis using Turkish data from 1986 to 2013, a much longer series than that of the existing research papers. Second, I use survey of inflationary expectations data to able to distinguish between the impact of ex-ante, expost inflationary expectations as well as expected and unexpected inflation on stock returns. Third, I conduct structural break analysis to identify structural breaks in the data and therefore evaluate Fisher hypothesis under different monetary regimes and inflationary environment. Finally, I rely not only on aggregate common stock market returns. I compile a panel Turkish stock market companies representing the common stock market dynamics to conduct empirical analysis at both company and industry levels. 


\section{Data description and preliminary empirics}

This study uses monthly frequency data covering the period from January 1986 to June 2013. All data is secondary and gathered from the Central Bank of Republic of Turkey's (CBRT) Electronic Data Delivery System, Turkish Statistical Institute’s online database, and Istanbul Stock Exchange's (ISE) website. I analyze stock returns using company level and aggregate data. Company level data is for a sample of one hundred and seventy major companies listed in Istanbul Stock Exchange covering a broad range of sub-industries. Banks and Special Financial Corporations, Basic Metal Industries, Chemicals, Petroleum Rubber and Plastic Products, Fabricated Metal Products, Machinery and Equipment, Food, Beverage and Tobacco, Textile, Wearing Apparel and Leather are some industries among the total of twenty six sub-industries under investigation. The number of companies, their industries, and sectorial nominal stock returns versus the common nominal stock market returns for periods consistent with structural break dates identified by Bai and Perron's $(1998,2003)$ structural breaks algorithm are given in Table 1. The sample of companies studied here is considered to reflect the entire Turkish stock market. For instance, the sample of companies covers one hundred and seventy of the three hundred and twenty four companies listed in ISE as of 2008. To get a better picture of the relationship between nominal stock returns and inflation, I constructed the sample consisting of major companies evaluated in terms of total assets, net sales, net profits, and market values. In addition, a selection criterion is applied for the sample where companies which were listed in ISE100 at least 4 years during the period of $1986-2013$ were added to the sample ${ }^{1}$. Table 2 summarizes the sample of companies under investigation, the periods during which these companies

\footnotetext{
${ }^{1}$ ISE100 (Istanbul Stock Exchange 100) index is a capitalization-weighted index composed of major national market companies except investment trusts.
} 
were listed in ISE100 in 2000-2013, their ISE ticker codes along with their total assets, net sales, net profits, and market values.

I use closing company level stock prices, $P_{i, t}$, and ISE100 price index values in the last trading day of each month to calculate nominal firm level stock returns, $R_{i, t}$, and average stock market return, $S R_{t}$, as $R_{i, t}=\left[\ln \left(P_{i, t} / P_{i, t-12}\right)\right] \times 100$ and $S R_{t}=$ $\left[\ln \left(I S E 100_{t} / I S E 100_{t-12}\right)\right] \times 100$, respectively. CPI inflation rates, $\pi_{t}$, are defined as the percentage change on the same month of the previous year. Figure 1 illustrates annual inflation rates versus nominal common stock market returns. I also utilize survey of inflationary expectations data conducted twice a month by CBRT since August $2001^{2}$. The survey of expectations collected the expectations of experts, decision makers from financial and real sectors, and professionals, pertaining to consumer price inflation (CPI), interest rates, exchange rate, current account balance and GNP growth rate. I use mode and arithmetic mean values of the expected CPI over the next twelve months. Monthly industrial production index numbers $(2010=100)$, daily interbank average overnight money market rates and M2 money stock are used to generate instruments for GMM estimation. In order to obtain deseasonalized industrial production index series I regress non-seasonally adjusted series on an intercept and eleven seasonal (month) dummies, recover the regression residuals and add original mean of the series to the residuals. I then apply Hodrick-Prescott filter to the natural logarithm of the

\footnotetext{
${ }^{2}$ Survey of expectations is started to be conducted once a month beginning from January 2013.
} 
deseasonalized industrial production index series to identify business cycles and construct output gap , $y_{t}$, as measured by percentage deviations from the trend ${ }^{3}$.

Figure 1. Annual inflation rates vs. Nominal common stock market returns

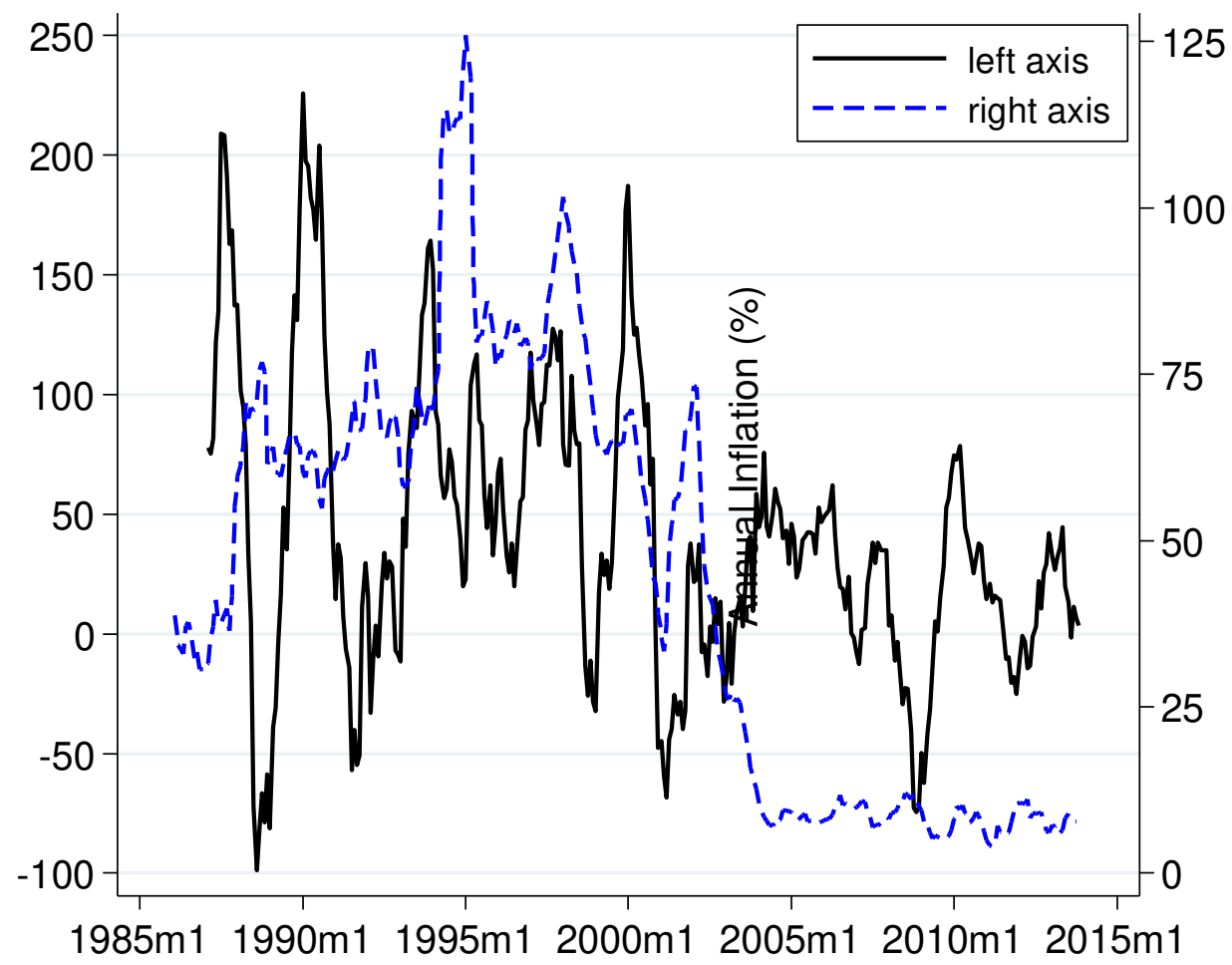

Notes: Data has monthly frequency covering the period from January 1986 to June 2013. Annual CPI inflation rates and common stock market returns are defined as the percentage change on the same month of the previous year.

Monthly average of interbank money market rates,$i_{t}$, are calculated using simple average of the daily interbank overnight rates. Annual M2 growth rates, m2, are calculated by the percentage change on the same month of the previous year.

Descriptive statistics for nominal common stock market returns and annual inflation rates for periods consistent with structural breaks are given in Table 3. Average nominal

\footnotetext{
${ }^{3}$ I also used output gap measures using quadratic and cubic detrending procedures in my estimations. The estimates are robust to output gap measures obtained using different detrending procedures.
} 
common stock market returns are more volatile and produced quantitatively bigger returns than the annual inflation rates. The relationship between inflation rates and returns is positive for the entire sample and for the period of $1994 \mathrm{~m} 4-2003 \mathrm{~m} 11$ whereas the correlation is negative for the periods of $1986 \mathrm{~m} 1-1994 \mathrm{~m} 3$ and $2003 \mathrm{~m} 12-2013 \mathrm{~m} 6$ suggesting no conclusive pattern of relationship.

Table 3. Descriptive statistics for common stock market returns and inflation rate

\begin{tabular}{ccccccc}
\hline & Mean & Median & SD & Skewness & Kurtosis & Correlation \\
\hline $1986 \mathrm{~m} 1-2013 \mathrm{~m} 6$ & & & & & & \\
$S R_{t}$ & 41.2775 & 35.0463 & 60.4145 & 0.5403 & 3.3137 & 0.2869 \\
$\pi_{t}$ & 45.0191 & 52.3900 & 32.1822 & 0.2171 & 1.9117 & \\
\hline $\begin{array}{c}1986 \mathrm{~m} 1-1994 \mathrm{~m} 3 \\
S R_{t}\end{array}$ & 63.6564 & 62.2619 & 84.2884 & 0.0394 & 1.9988 & \\
$\pi_{t}$ & 59.0481 & 63.1350 & 13.6800 & -0.8986 & 2.5431 & -0.4486 \\
$1994 \mathrm{~m} 4-2003 \mathrm{~m} 11$ & & & & & & \\
$S R_{t}$ & 46.2578 & 42.3453 & 53.5690 & 0.0640 & 2.4339 & \multirow{2}{*}{0.4681} \\
$\pi_{t}$ & 69.4756 & 71.2600 & 26.0853 & -0.0930 & 2.5658 & \\
$2003 \mathrm{~m} 12-2013 \mathrm{~m} 6$ & & & & & & \\
$S R_{t}$ & 19.5184 & 26.7370 & 32.3199 & -0.7889 & 3.4982 & -0.2490 \\
$\pi_{t}$ & 8.3949 & 8.3700 & 1.8297 & -0.1686 & 2.6860 & \\
\hline
\end{tabular}

Notes: Data has monthly frequency covering the period from January 1986 to June 2013. The periods are constructed based on the structural break dates of Apr'95 and Dec' 03 which are estimated by Bai and Perron's $(1998,2003)$ multiple structural breaks optimization procedure.

Dealing with time series modelling involves tests to determine whether a series possesses unit root. I use Dickey-Fuller generalized least squares (GLS) unit root test proposed by Elliott, Rothenberg, and Stock (1996) with improved, efficient and best overall statistical performance to identify unit root in the series if any. Table 4A displays Dickey-Fuller GLS unit root test results. According to Table 4A stock returns and output gap series are stationary at conventional significance levels whereas inflation rates, money market and M2 growth series are not trend stationary ${ }^{4}$.

\footnotetext{
${ }^{4}$ I also applied augmented Dickey-Fuller unit root test. Both Dickey-Fuller GLS and standard Dickey-Fuller unit root tests give statistically similar results.
} 
Table 4A. Dickey-Fuller generalized least squares (DF-GLS) unit root tests

\begin{tabular}{cccc}
\hline Variables & $\begin{array}{c}\text { Lag } \\
\text { length }\end{array}$ & $\begin{array}{c}\text { Intercept term, } \\
\text { and no time trend }\end{array}$ & $\begin{array}{c}\text { Intercept term, } \\
\text { and time trend }\end{array}$ \\
\hline$S R_{t}$ & 14 & -2.042 & -3.993 \\
$\pi_{t}$ & 15 & -0.594 & -0.878 \\
$\pi^{a}{ }_{t}$ & 8 & 0.114 & -1.140 \\
$\pi^{b}{ }_{t}$ & 7 & -0.029 & -1.115 \\
$y_{t}$ & 16 & -1.495 & -3.043 \\
$i_{t}$ & 10 & -0.737 & -1.098 \\
$\mathrm{~m} 2$ & 14 & -1.294 & -1.646 \\
\hline
\end{tabular}

Notes: Data has monthly frequency covering the period from January 1986 to June 2013. Lag length are optimized using the Ng-Perron optimal lag selection criterion. $1 \%, 5 \%$ and $10 \%$ critical values for rejection of the null hypothesis of a unit root are $-2.580,-1.959$, and -1.645 respectively for the model with intercept term and no time trend. When a linear time trend is included in addition to an intercept term, the critical values become -3.480, 2.825 , and -2.544 , respectively. $\pi^{a}{ }_{t}$ and $\pi^{b}{ }_{t}$ are the expected mean and mode inflation series from the survey of expectations.

In order to obtain stationary series, I take the first difference of inflation rates, money market and M2 growth series ${ }^{5}$. Since the inflation rate series are subject to structural breaks, standard Dickey-Fuller tests may result in incorrect conclusions. Hence, for sensitivity analysis and more reliability, I use Clemente, Montanés, and Reyes (1998) unit root tests with double mean shifts (two-breaks), IO model allowing for a gradual

${ }^{5}$ About the currency crisis of 1994 and financial crisis of February 2001, money market rates skyrocketed exceeding 190\% overnight. There are four data points during 1994 crisis and two data points during financial crisis of 2001 which exceed $190 \%$. When original money market series is tested for unit roots, the series are found to be stationary. The unit root test statistics for the original series are -2.567 (intercept term and no time trend) and -2.770 (intercept term and time trend) with an optimized Ng-Perron lag length of eight. Whereas when the outlier six data points are replaced with data points generated by linear interpolation, the money market series are found to be difference stationary as shown in Table 4A. In addition, dropping the six outlier data points in the money market rates increases the simple correlation between money market and inflation rate series from about $60 \%$ to $90 \%$ which supports the use of money market series without the outlier data points. 
shift in the mean of the series and AO model capturing sudden changes in the mean of the series. Table 4B displays the results for Clemente, Montanés, and Reyes (1998) unit root tests with double mean shifts. The results are in line with the Dickey-Fuller GLS unit root test results displayed in Table 4A. Innovative outlier case for the inflation rate in Table 4B shows that we cannot reject the null hypothesis of a unit root in the inflation series despite the estimated structural breaks at Mar'94 and Jan'02. According to additive outlier case in Table 4B, despite the estimated structural breaks at Feb'94 and Feb'03, both are significant at 5\% significance level, we cannot reject the null hypothesis of a unit root in the inflation rate series ${ }^{6}$.

\section{The model and empirical methodology}

Generalized Fisher equation suggests that the nominal interest rate can be expressed as the sum of an expected real return and expected inflation rate (Irving Fisher, 1930). Fisher's this proposition can be applied to all assets including common stocks. Fama and Schwert (1977) formally describes generalized Fisher effect by

$$
E_{t-1} R_{i, t}=E_{t-1} r_{i, t}+E_{t-1} \pi_{t}
$$

where $R_{i, t}$ and $r_{i, t}$ are the nominal and real returns on any asset $i$, respectively, $\pi_{t}$ is the rate of inflation, and $E_{t-1}$ is efficient market expectations operator conditional on all available information at time $t-1$.

\footnotetext{
${ }^{6}$ Note that the estimated structural breaks of the Clemente, Montanés, and Reyes (1998) testsFeb'94 and Feb'03-are aligned with the break dates-Apr'94 and Dec'03- estimated by Bai and Perron's $(1998,2003)$ structural break procedure described in section V.
} 
Table 4B. Clemente, Montanés, and Reyes (1998) unit root tests with double mean shifts.

\begin{tabular}{|c|c|c|c|c|c|c|c|c|c|}
\hline & $\widehat{\mu}$ & $\widehat{\boldsymbol{d}}_{1}$ & $\hat{\boldsymbol{t}}_{\mathbf{d} 1}$ & $\mathbf{T}_{\mathbf{B 1}}$ & $\widehat{d}_{2}$ & $\hat{\boldsymbol{t}}_{\mathrm{d} 2}$ & $\mathbf{T}_{\mathbf{B} 2}$ & $\widehat{\rho}^{-1}$ & $\min _{\widehat{\rho}}$ \\
\hline \multicolumn{10}{|c|}{ Innovative outlier (IO) case } \\
\hline$\pi_{t}$ & 3.3549 & -0.0583 & -0.138 & $1994 \mathrm{~m} 3$ & -3.0491 & $-4.285 * *$ & $2002 \mathrm{~m} 1$ & -0.0476 & -4.285 \\
\hline$S R_{t}$ & -4.7714 & 22.2613 & $2.778 * *$ & $1988 \mathrm{~m} 12$ & -13.6072 & $-2.967 * *$ & 1990m6 & -0.1212 & -4.304 \\
\hline \multicolumn{10}{|c|}{ Additive outlier (AO) case } \\
\hline$\pi_{t}$ & 58.8782 & 14.6094 & $6.878 * *$ & $1992 \mathrm{~m} 2$ & -64.1432 & $-32.332 * *$ & $2003 \mathrm{~m} 2$ & -0.0829 & -3.634 \\
\hline$S R_{t}$ & 55.8840 & 128.1383 & $5.500 * *$ & $1989 \mathrm{~m} 10$ & -148.6097 & $-6.937 * *$ & $1990 \mathrm{~m} 5$ & -0.1105 & -3.175 \\
\hline
\end{tabular}

Notes: Data has monthly frequency covering the period from January 1986 to June 2013 . $* *$ shows statistical significance at $5 \%$ significance level. $\mathrm{T}_{\mathrm{B} 1}$ and $\mathrm{T}_{\mathrm{B} 2}$ are the estimated break dates. 
According to Fisher hypothesis, expected real return on any asset in (1) is determined by real factors like the productivity of capital, investor time preferences, and taste for risk, and that the expected real return and the expected inflation rate are independent. Empirical studies investigating the Fisher effect have also shown that expected real rate is constant i.e. $E_{t-1} r_{i, t}=\bar{r}$. Under rational expectations, expected nominal returns on an asset can be written as following.

$$
R_{i, t}=E_{t-1} R_{i, t}+\epsilon_{i, t}
$$

where $\epsilon_{i, t}$ stands for i.i.d error terms with zero mean.

Making appropriate changes and substituting equation (2) and $E_{t-1} r_{i, t}=\bar{r}$ into (1) gives the following relationship for any asset $i$

$$
R_{i, t}=\bar{r}+E_{t-1} \pi_{t}+\epsilon_{i, t}
$$

Equation (3) provides a basis for the following panel regression model (4) for empirical testing of the Fisher effect using company level nominal stock returns data.

$$
R_{i, t}=\alpha_{i}+\beta E_{t-1} \pi_{t}+u_{i, t}
$$

where $\alpha_{i}$ is the unknown is intercept for any company $i, \beta$ is the common slope coefficient, and $u_{i, t}$ is the error term. The empirical model in (4) can be re-written for nominal common stock market returns as

$$
S R_{t}=\alpha+\beta E_{t-1} \pi_{t}+u_{t}
$$

where $S R_{t}$ are nominal stock market returns, $\alpha$ is the intercept, $\beta$ is the slope coefficient, and $u_{t}$ is the common error term.

Given that an appropriate measurement for expected inflation is used, an estimate of $\beta=1$ is consistent with the Fisher effect where a one percent increase in expected inflation rate yields a one percent increase in expected nominal return. This suggests stock returns provides one hundred percent hedge against inflation. Crowder 
and Hoffman (1996) reported that when tax effects are considered, the Fisher effect may not confirm to a one-to-one correspondence claiming $\beta \geq 1$.

This study uses the regression models depicted in (4) and (5) to empirically evaluate the hypothesis whether stock returns provide a good hedge against inflation i.e. whether Fisher effect exists in stock returns. I use a panel of company level stock returns data and Turkish common stock market indices covering the period from January 1986 to June 2013. Anecdotal and statistical evidence suggest that the period under investigation is subject to structural changes. I apply Bai and Perron's (1998, 2003) multiple structural break analysis along with anecdotal notes to identify structural break dates in the data ${ }^{7}$. That way, I obtain a modified versions of the regression models in (4) and (5) with structural breaks as

$$
\begin{aligned}
& R_{i, t}^{j}=\alpha_{i}^{j}+\beta^{j} E_{t-1} \pi_{t}+u_{i, t} \\
& S R_{t}=\alpha^{j}+\beta^{j} E_{t-1} \pi_{t}+u_{t}
\end{aligned}
$$

where $j=1, \ldots, m+1$, and $m$ stands for number of structural breaks. In this formulation, $j=1$ would mean no structural break in the regression model, or $j=2$ would mean that there is a single structural break splitting the regression model into two parts with significantly different model estimates.

The regression models in (6) and (7) contain inflationary expectations which are not directly observable. Therefore, appropriate measurements for expected inflation must be used to estimate the models. I first use the actual inflation rate series as a proxy for inflationary expectations and conduct Ordinary Least Squares (OLS) estimation

\footnotetext{
${ }^{7}$ Multiple structural break dates analysis is carried out using the Gauss code made available by Bai and Perron's $(1998,2003)$. The Gauss code can be accessed online at http://people.bu.edu/perron/code/m-Break.zip
} 
method. Second, I undertake single-equation Generalized Method of Moments (GMM) estimation procedure consistent with endogenous expectation terms that appear in the regression models. Finally, I estimate the regression models in (6) and (7) using inflationary expectations survey data collected by the Central Bank of the Republic of Turkey since August 2001.

In order to be able to evaluate the impact of unexpected inflation rate on returns, I estimate the following empirical panel of company level and common stock returns models

$$
\begin{gathered}
R_{i, t}^{j}=\alpha_{i, t}^{j}+\beta_{1}^{j} E_{t-1} \pi_{t}+\beta_{2}^{j}\left(\pi_{t}-E_{t-1} \pi_{t}\right)+u_{i, t} \\
S R_{t}=\alpha^{j}+\beta_{1}^{j} E_{t-1} \pi_{t}+\beta_{2}^{j}\left(\pi_{t}-E_{t-1} \pi_{t}\right)+u_{t}
\end{gathered}
$$

where $E_{t-1} \pi_{t}$ is the expected inflation rate over the next twelve months from CBRT survey data, and therefore $\pi_{t}-E_{t-1} \pi_{t}$ is the unexpected inflation rate. I report all model estimates in section $\mathrm{V}$.

\section{Empirical analysis and results}

Table 5 displays the results of the $\operatorname{SupF}(m \mid 0)$ and $\operatorname{SupF}(m+1 \mid m)$ tests and the estimated break dates in the annual inflation rate, common stock prices and nominal return series identified by Bai and Perron's $(1998,2003)$ multiple structural break optimization procedure. The $\operatorname{Sup} F(m \mid 0)$ test evaluates the null hypothesis that there exists zero structural break dates against the alternative hypothesis of certain number of unknown break dates exist in the data. On the other hand, $\operatorname{Sup} F(m+1 \mid m)$ test provides a sequential method for choosing the number of breaks when the $\operatorname{Sup} F(m \mid 0)$ test has confirmed the existence of at least one break in the data. I allowed maximum of five structural breaks in each of the series. Panel A of Table 5 displays the test results for the annual inflation rates. $\operatorname{Sup} F(m \mid 0)$ test statistics for maximum of five structural 
Table 5. Bai and Perron's (1998) structural break tests

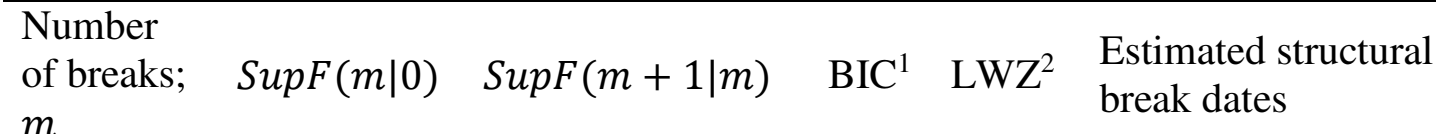

A. Annual mean values of inflation rates

\begin{tabular}{llllll}
1 & $10.86 * *$ & $15.74 * * *$ & -- & $2003 \mathrm{~m} 12$ \\
& & -- & & $(2003 \mathrm{~m} 11-2005 \mathrm{~m} 2)$ \\
2 & $12.46 * * *$ & 6.83 & 2 & 0 & $1994 \mathrm{~m} 4$ \\
3 & $14.35 * * *$ & 3.98 & 2 & 0 & -- \\
4 & $11.18 * * *$ & 0.89 & -- & -- & -- \\
5 & $9.35 * * *$ & -- & 3 & 0 & -- \\
\hline
\end{tabular}

B. Common stock market prices

\begin{tabular}{llllll}
1 & $27.73 * * *$ & $36.73 * * *$ & - & -- & $2005 \mathrm{~m} 12$ \\
& & - & & $(2005 \mathrm{~m} 5-2006 \mathrm{~m} 1)$ \\
2 & $14.62 * * *$ & $25.10 * * *$ & -- & -- & $(1999 \mathrm{~m} 11$ \\
& & & & $1996 \mathrm{~m} 6-1999 \mathrm{~m} 12)$ \\
3 & $13.34 * * *$ & $25.10 * * *$ & -- & -- & $(1995 \mathrm{~m} 10$ \\
4 & $13.70 * * *$ & 0.09 & -- & -- & -- \\
5 & $11.02 * * *$ & -- & 3 & 3 & -- \\
\hline
\end{tabular}

C. Nominal common stock market returns

\begin{tabular}{llllll}
1 & $9.24 * *$ & 1.94 & -- & -- & $1999 \mathrm{~m} 11$ \\
2 & $6.32 *$ & 1.69 & -- & -- & -- \\
3 & 4.36 & 1.69 & -- & -- & -- \\
4 & 3.49 & 6.79 & -- & -- & -- \\
5 & 4.08 & -- & 0 & 0 & -- \\
\hline
\end{tabular}

Notes: Data has monthly frequency covering the period from January 1986 to June 2013. The model $X_{t}^{j}=a^{j}+b X_{t-1}+\vartheta$, where $j=1,2, \ldots m+1$, is estimated allowing the mean values to change where the slope coefficient is constant across sub-samples identified by the structural break dates found in the data. $X$ stands for the annual inflation rates, common stock market prices, and nominal common stock market returns in parts A, B, and C, respectively. Reported estimated structural break dates are based on sequential method at significance level 5\%.

${ }^{1}$ BIC: Bayesian Information Criteria.

${ }^{2} \mathrm{LWZ}$ is the modified Schwarz criterion proposed by Liu, Wu, and Zidek (1997).

$* * * \mathrm{p}<0.01, * * \mathrm{p}<0.05$, and $* \mathrm{p}<0.10$.

The residuals are pre-whitened using a $A R(1)$ process.

In parentheses are the $95 \%$ upper and lower confidence levels.

break dates are all statistically significant at $5 \%($ for $\mathrm{m}=1)$ and $1 \%$ for $(\mathrm{m}=2,3,4$, and 5)

significance levels when compared to critical values from the table in Bai and Perron (1998). The sequential $\operatorname{SupF}(m+1 \mid m)$ test statistics are significant at $1 \%$ significance level up to two break dates. That is, given the existence of one break as suggested 
by $\operatorname{Sup} F(1 \mid 0)=10.86, \operatorname{SupF}(2 \mid 1)=15.74$ suggest that there exist a second break date. The next test statistic $\operatorname{SupF}(3 \mid 2)=6.83$ is below the critical value suggesting that there are only two breaks in the inflation series. The estimated structural break dates are December 2003 and April 1994 with 95\% confidence intervals of (2003m112005m2) and (1990m12-1997m3), respectively. The confidence interval for the first break date is very tight, covering minus one, plus fourteen months, suggesting more reliable estimation.

Panel B of Table 5 displays the test results for the common stock market prices. $\operatorname{SupF}(m \mid 0)$ test statistics for maximum of five structural break dates are all statistically significant at $1 \%$ significance levels. The sequential $\operatorname{SupF}(m+1 \mid m)$ test statistics are significant at $1 \%$ significance level up to three break dates. That is, given the existence of two breaks as suggested by $\operatorname{Sup} F(1 \mid 0)=14.62, \operatorname{Sup} F(3 \mid 2)=15.10$ suggest that there exist a third break date. The estimated structural break dates in the common stock market prices are December 2005, November 1999, and October 1995 with 95\% confidence intervals of (2005m5-2006m1), (1996m6-1999m12), and (1995m101995m10), respectively. The confidence interval for the first and third break dates are very tight suggesting more reliable estimation. Panel $\mathrm{C}$ of Table 5 displays the test results for the nominal common stock market returns. The sequential test statistics are not significant at all, while the $\operatorname{Sup} F(m \mid 0)$ test statistics for maximum of two structural break dates are statistically significant at $5 \%$ significance levels. These tests suggest a single structural break date exist at November 1999. The reported $95 \%$ confidence interval of (1998m3-2010m8) is extremely large putting doubts on the estimates.

The estimated structural break dates, with relatively tight $95 \%$ confidence intervals, of Dec'2003 and Apr'1994 in the inflation rate series and Dec'2005 and Oct'1995 in the common stock market prices are aligned. Moreover, anecdotal evidence 
also suggests close estimates for structural breaks in the data. For instance, the estimated break dates of Dec'03 and Dec'05 coincides with the date of the announcement made by the CBRT in Jan'04 that it will switch to full-fledged inflation targeting beginning Jan'06. In addition, the estimated breaks in Apr'1994 and Oct'1995 are in line with the currency crisis in 1994 and the sharp response of the Turkish government, the so-called the April $5^{\text {th }}$ Resolutions of 1994, aiming to stabilize the economy and curb the inflation rate. Therefore, I decide to operate by allowing structural break dates of Apr'95 and Dec'03 supported by the anecdotal evidence and which have narrower confidence intervals suggesting more reliability.

An alternative and a quicker way of analyzing the impact of structural breaks on model coefficients is to use rolling regressions. I estimate the regression model in (5) using rolling window estimation procedure. I allow different length for the sub-periods to study whether the estimates for $\beta$ coefficient change considerably over time. I use alternative window lengths of $30,36,42$, and 48 months $(2.5,3,3.5$ and 4 years). Figure 2 presents rolling window estimates for $\beta$ coefficient of the regression model in $(5)^{8}$. According to Figure 2, there are significant shifts in the estimates for $\beta$ coefficient as seen around the vertical dashed lines. I consider this as an evidence for the existence of structural breaks in the data and therefore the estimations should take this finding into account.

The regression models in 6 and 7 are estimated using OLS and GMM methods using returns for companies (disaggregated data) and nominal common stock market returns (aggregated data) and, respectively. I first explain the findings using the nominal

\footnotetext{
${ }^{8}$ I used actual current inflation rates as proxies for expected inflation rates in the rolling window estimation procedure.
} 
Figure 2. Rolling window estimates for $\beta$ coefficient ( \pm 2 SD)

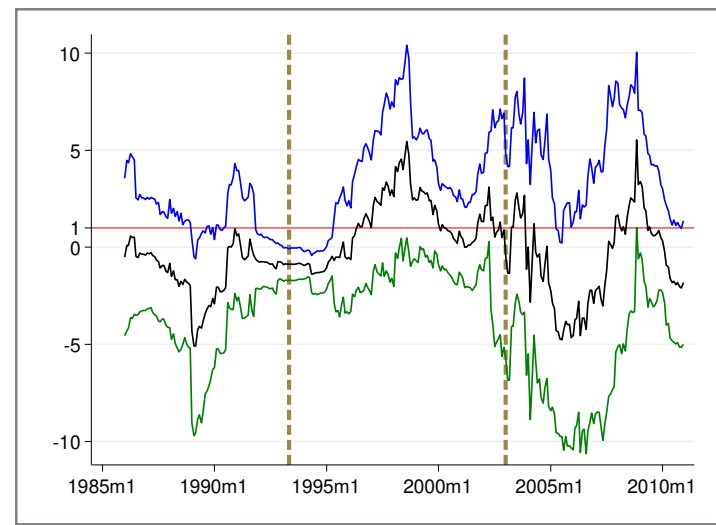

Window size 30 months.

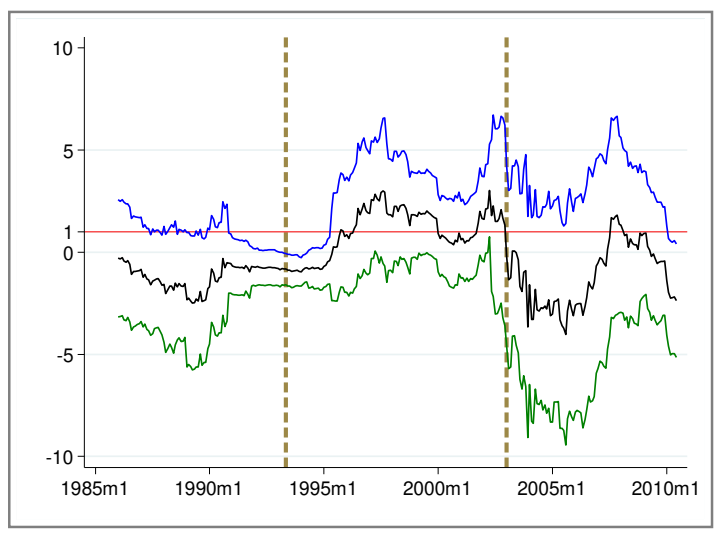

Window size 42 months.

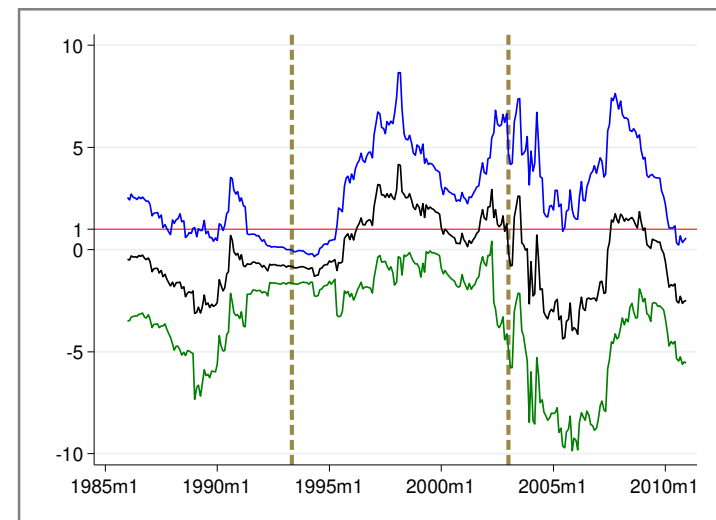

Window size 36 months.

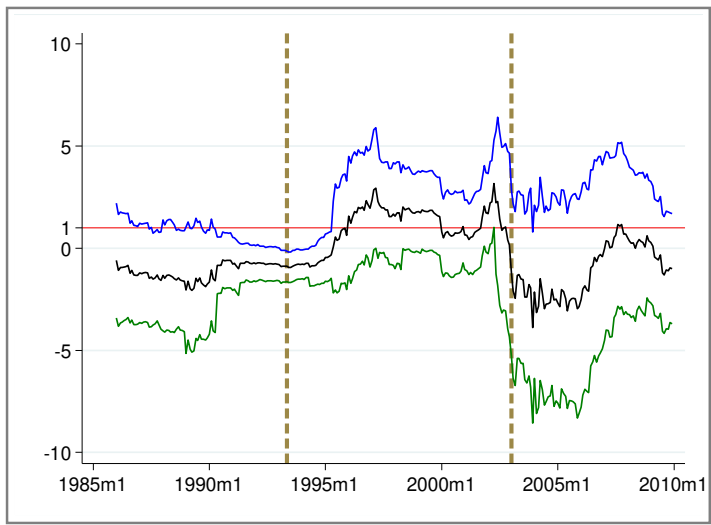

Window size 48 months.

Notes: Data has monthly frequency covering the period from January 1986 to June 2013. The diagrams show evolution of $\beta$ coefficient obtained from OLS estimation of the following regression model: $S R_{t}=$ $\alpha+\beta E_{t-1} \pi_{t}+\psi_{t}$. Dashed vertical lines are drawn at the structural break dates of Apr'94 and Dec'03 estimated by Bai and Perron (1998, 2003).

common stock market returns. Tables $6 \mathrm{~A}$ and $6 \mathrm{~B}$ display the estimates for the coefficients in model 7. To capture the short-run dynamics of the returns lagged returns are added to the model for control purposes. The OLS estimates in Table 6A show a significant autocorrelation property in the nominal common stock returns whereas no statistically significant Fisher effect is found ${ }^{9}$. The Fisher's $\beta$ coefficient is negative for

\footnotetext{
${ }^{9}$ OLS estimates are obtained using actual current inflation rates as proxies for expected inflation rates.
} 
for the entire sample and for all sub-samples identified by the structural break dates.

To conduct single equation GMM estimation procedure, I use an instrument set of a constant, three lags of inflation rates, money market rates, M2 annual growth rates, and twelve lags of output gap. Column 0 show the estimates for the entire sample plus columns 1, 2, and 3 give estimates for the periods of 1986m1-1994m3, 1994m42003m11, and 2003m12-2013m6, respectively. The coefficient on the expected inflation term is negative and significant at conventional significance levels for all periods except the period of 2003m12-2013m6. Hansen's J statistics in columns 1, 2, 3 and 4 are small enough to reject the joint null hypothesis that instruments are valid and that the excluded instruments are correctly excluded from the estimated model. However, Kleibergen-Paap rk Wald F statistics for weak identification test fails to reject the null hypothesis of weak instruments when evaluated at the Stock and Yogo's (2005) critical values for weak identification test. Stock and Yogo (2005) discuss in detail that when instruments are weak i.e. excluded instruments are correlated with endogenous regressors but only weakly, estimators can perform poorly when instruments are poor.

The OLS estimates using expectations survey data by the CBRT displayed in Table 6B provides some evidence for the Fisher's $\beta$ coefficient that the estimates suggest $\beta>1$. The estimates using mode vs. arithmetic mean values of the survey of inflationary expectations are larger confirming the possible downward bias when the data points are averaged. The estimate -1.3036 in front of the unexpected inflation term in model 3 suggests a negative relationship between the nominal common stock market returns and unexpected inflation. Though the estimates in Table $6 \mathrm{~B}$ for the Fisher's $\beta$ coefficient and the unexpected inflation term are in line with the theoretical considerations, none of the estimates are statistically significant. 
Table 6A. Standard OLS and GMM estimates

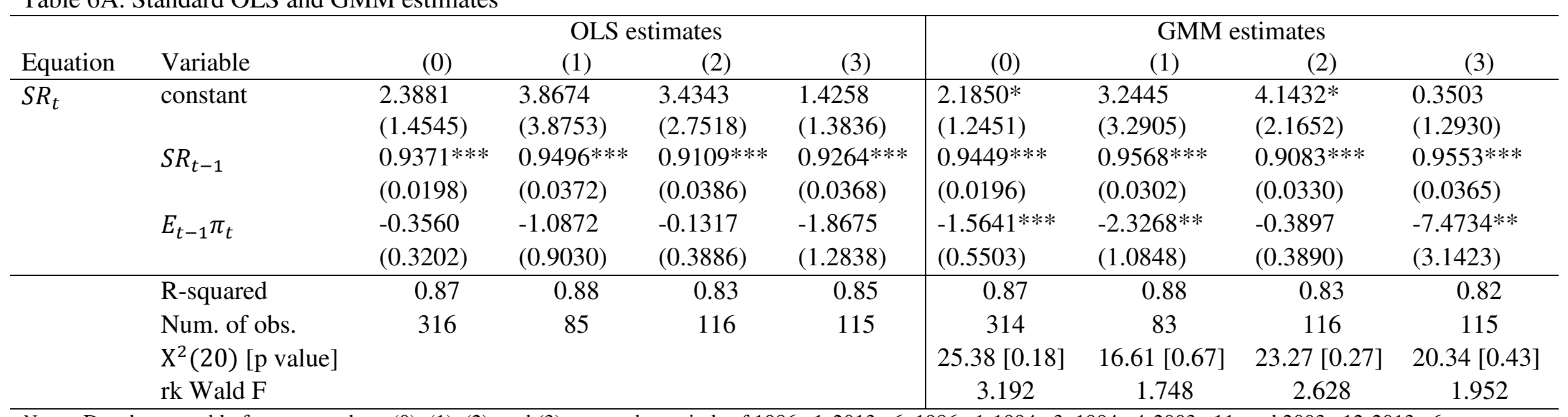

Notes: Data has monthly frequency where (0), (1), (2), and (3) covers the periods of 1986m1-2013m6, 1986m1-1994m3, 1994m4-2003m11, and 2003m12-2013m6,

respectively. $* * * \mathrm{p}<0.01, * * \mathrm{p}<0.05, * \mathrm{p}<0.10$. Robust standard errors are in the parentheses underneath the coefficients. The GMM instruments set includes a constant, three lags of inflation rates, twelve lags of output gap, three lags of money market rates, and three lags of M2 annual growth rates. $\mathrm{X}^{2}(20)$ stands for the J-statistic and (the number of over identifying restrictions). rk Wald F stands for the Kleibergen-Paap rk Wald F statistics.

Table 6B. Standard OLS estimates using expectations survey data

\begin{tabular}{clccc}
\hline Equation & Variable & $(1)$ & $(2)$ & $(3)$ \\
\hline$S R_{t}$ & constant & 2.2610 & 2.1447 & 1.8305 \\
& & $(1.3835)$ & $(1.4067)$ & $(1.4255)$ \\
& $S R_{t-1}$ & $0.9051^{* * *}$ & $0.9018^{* * *}$ & $0.9120^{* * *}$ \\
& & $(0.0381)$ & $(0.0382)$ & $(0.0384)$ \\
& $E_{t-1} \pi_{t}$ & 1.3177 & 0.7286 & 0.0577 \\
& & $(0.9463)$ & $(1.1898)$ & $(1.4013)$ \\
& $\pi_{t}-E_{t-1} \pi_{t}$ & & & -1.3036 \\
& & & & $(1.0710)$ \\
\hline & R-squared & 0.81 & 0.81 & 0.81 \\
& Num. of obs. & 130 & 130 & 130 \\
\hline
\end{tabular}

Notes: The data is monthly covering the period from August 2001 to June 2013. Models (1) and (2) uses mode and arithmetic mean values of the expected CPI values. Model (3) is the same model with (1) except for the additional unexpected inflation term. *** $\mathrm{p}<0.01, * * \mathrm{p}<0.05, * \mathrm{p}<0.10$. 
Next, I move on to the estimation for the model described by equation 6 using the panel of Turkish companies. Companies operating in different industries may have different responses, as reflected in their stock returns, to the changes in the inflation rate due to the differences in the extent of raw materials usage, energy needs. That is to say, I don't expect the variation across companies to be random which suggests the use of fixed effects regression against the random effects regression of panel data estimation. For statistical and precision purposes, I conduct Hausman specification test to choose between fixed and random effect models where the null hypothesis is that the preferred model is random effects vs. the alternative is fixed effects. Hausman test results displayed in Table 7 are also in favor fixed effects estimation of the panel data.

Table 7. Hausman specification test

\begin{tabular}{|c|c|c|c|c|}
\hline Test summary & \multicolumn{2}{|c|}{ Chi-Sq. statistics (Chi-Sq. d.f.) } & \multicolumn{2}{|l|}{ Prob. } \\
\hline $\begin{array}{l}\text { Cross-section } \\
\text { random }\end{array}$ & $18.55(2)$ & & 0.0001 & \\
\hline Cross-section 1 & $m$ effects test comparis & & & \\
\hline Variable & Fixed & Random & Difference & Prob. \\
\hline$R_{i, t-1}$ & 0.8984 & 0.8999 & -0.0014 & 0.0003 \\
\hline$E_{t-1} \pi_{t}$ & -.1078 & -0.1025 & -0.0053 & 0.0045 \\
\hline
\end{tabular}

I obtain a Chi-squared test statistics of 18.55 rejecting the null hypothesis at $1 \%$ significance level.

Table 8 displays fixed effects panel data estimates for the regression model described by equation $6^{10}$. Left panel in Table 8 show OLS estimates whereas the right panel show instrumental variables (IV) two-stage least-squares estimates. OLS estimates in columns

${ }^{10}$ Company stock returns, inflation and other data that enter the estimation have been meandifferenced (or first-differenced in some cases) to correctly produce IV-GMM estimates for panel data. 
$0,1,2$, and 3 show a negative relationship between the inflation rates and nominal stock returns at $5 \%$ and $10 \%$ significance levels (except the estimate in column 2). To account for endogenous inflationary expectations, I conduct single equation two-stage least squares fixed effects model (within estimator) where I use IV instruments set of a constant, three lags of inflation rates, money market rates, M2 annual growth rates, and twelve lags of output gap. The coefficient on the expected inflation term is negative and significant at conventional significance levels for all periods, columns 1, 2, and 3 except the estimate for the entire period of 1986m1-2013m6. Statistically significant estimates in front of the expected inflation term, $-2.7547,-0.4721$, and -4.7936 for different subperiods show that there are large differences in Fisher's $\beta$ effect across periods. The estimates must be evaluated with suspicion since over identification test statistics (not reported) are large rejecting the joint null hypothesis that instruments are valid and that the excluded instruments are correctly excluded from the estimated fixed effects model.

Fixed effects panel data model estimates using expectation survey data of the CBRT are displayed in Table 9A. The estimate for the Fisher effect is consistently positive and larger than unity. For instance, the estimate $\hat{\beta}=1.7517$ for the period of Aug'01-Jun'13 conjectures that a one percent increase in the expected inflation rate yields a subsequent 1.75 percent rise in the nominal stock returns. When unexpected inflation term is taken into account, I obtain an estimate of $\hat{\beta}=1.5255$ and a negative coefficient of -0.2308 in front of the unexpected inflation. These finding confirms the existence of Fisher effect in line with Crowder and Hoffman's (1996) conclusions where when tax effects are considered, the Fisher effect may not confirm to a one-toone correspondence, and unexpected inflation has negative impact of nominal stock returns. 
Table 8. Panel data estimates

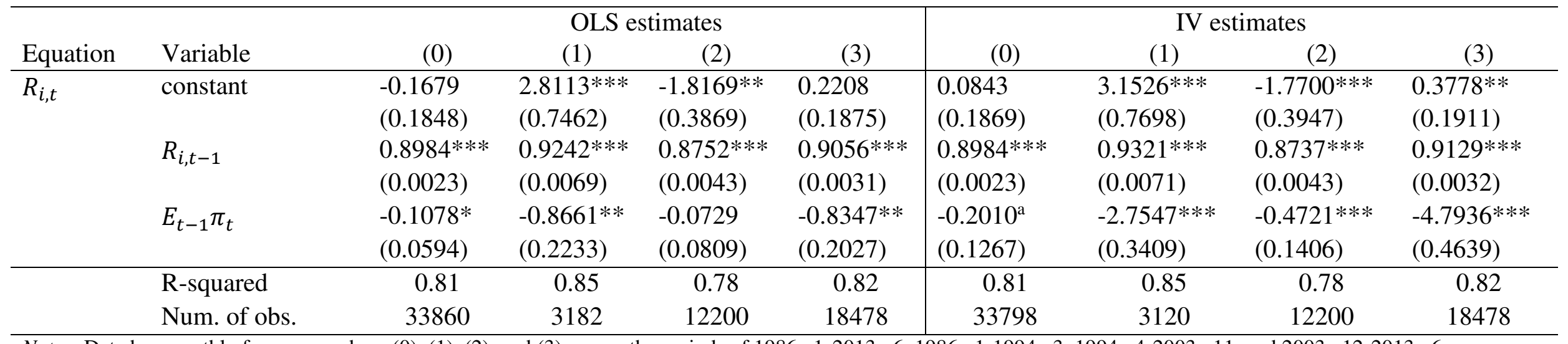

Notes: Data has monthly frequency where (0), (1), (2), and (3) covers the periods of 1986m1-2013m6, 1986m1-1994m3, 1994m4-2003m11, and 2003m12-2013m6,

respectively. $* * * \mathrm{p}<0.01, * * \mathrm{p}<0.05,{ }^{*} \mathrm{p}<0.10$, and $\mathrm{a}<0.15$. Standard errors are in the parentheses underneath the coefficients. OLS estimates are obtained using actual current inflation rates as proxies for expected inflation rates. The IV instruments set includes a constant, three lags of inflation rates, twelve lags of output gap, three lags of money market rates, and three lags of M2 annual growth rates. 
Table 9A. Panel data estimates using expectations survey data

\begin{tabular}{clccc}
\hline Equation & Variable & $(1)$ & $(2)$ & $(3)$ \\
\hline$R_{i, t}$ & constant & $0.4542^{* *}$ & $0.3400^{* *}$ & $0.4055^{* *}$ \\
& & $(0.1886)$ & $(0.1912)$ & $(0.1919)$ \\
& $R_{i, t-1}$ & $0.8995^{* * *}$ & $0.8988^{* * *}$ & $0.9000^{* * *}$ \\
& & $(0.0030)$ & $(0.0030)$ & $(0.0030)$ \\
& $E_{t-1} \pi_{t}$ & $1.7517^{* * *}$ & $1.3429^{* * *}$ & $1.5255^{* * *}$ \\
& & $(0.1535)$ & $(0.1930)$ & $(0.2252)$ \\
& $\pi_{t}-E_{t-1} \pi_{t}$ & & & $-0.2308^{\mathrm{b}}$ \\
& & & & $(0.1681)$ \\
\hline & R-squared & 0.82 & 0.81 & 0.82 \\
& Num. of obs. & 20598 & 20598 & 20598 \\
\hline
\end{tabular}

Notes: Data has monthly frequency covering the period from August 2001 to June 2013. Models (1) and (2) uses mode and arithmetic mean values of the expectations survey data. Model (3) is the same model with (1) except for the additional unexpected inflation term. *** p $<0.01, * * \mathrm{p}<0.05, * \mathrm{p}<0.10$, and $\mathrm{b}<0.20$. Standard errors are in the parentheses underneath the coefficients.

Having panel data of one hundred and seventy firms operating in different industries give me the opportunity to evaluate the Fisher effect for different industries. Table 9B display fixed effects model estimates for manufacturing and service industry firms using survey of expectations data. I find statistical evidence for the existence of Fisher effect in both manufacturing and service industries where the effect is larger for Table 9B. Industry-based panel data estimates using expectations survey data

\begin{tabular}{clcccc}
\hline & \multicolumn{3}{c}{$\begin{array}{c}\text { Panel of } \\
\text { manufacturing industry firms }\end{array}$} & \multicolumn{2}{c}{ Panel of } \\
service industry firms \\
\hline Equation & Variable & $(1)$ & $(2)$ & $(1)$ & $(2)$ \\
\hline$R_{i, t}$ & constant & $0.5376^{* *}$ & $0.5244^{* *}$ & 0.3730 & 0.2732 \\
& & $(0.2556)$ & $(0.2607)$ & $(0.2822)$ & $(0.2865)$ \\
& $R_{i, t-1}$ & $0.8999^{* * *}$ & $0.9001^{* * *}$ & $0.8998^{* * *}$ & $0.9008^{* * *}$ \\
& & $(0.0041)$ & $(0.0041)$ & $(0.0044)$ & $(0.0044)$ \\
& $E_{t-1} \pi_{t}$ & $1.8902^{* * *}$ & $1.8337^{* * *}$ & $1.6374^{* * *}$ & $1.1377^{* * *}$ \\
& & $(0.2021)$ & $(0.2996)$ & $(0.2362)$ & $(0.3428)$ \\
& & & -0.0577 & & $-0.5093^{* *}$ \\
& $\pi_{t}-E_{t-1} \pi_{t}$ & & $(0.2260)$ & & $(0.2533)$ \\
\hline & R-squared & 0.81 & 0.81 & 0.82 & 0.82 \\
& Num. of obs. & 11172 & 11172 & 9167 & 9167 \\
\hline
\end{tabular}

Notes: Data has monthly frequency covering the period from August 2001 to June 2013. All model estimates are obtained using mode values of the expectations survey data. $* * * p<0.01$, $* * \mathrm{p}<0.05, * \mathrm{p}<0.10$, and $\mathrm{b}<0.20$. Standard errors are in the parentheses underneath the coefficients. 
firms operating in manufacturing industry. The model estimates are $\hat{\beta}=1.8902$ and $\hat{\beta}=1.6374$ for manufacturing industry firms and service industry firms, respectively. The model estimates suggest a one percent rise in inflation rate increases the nominal stock returns by more than one percent suggesting that stock returns provide a good hedge against inflation. Unexpected inflation seems to have negative impact on stock returns no matter in which industry the firms are operating at. However, the negative impact of unexpected inflation is both statistically significant and larger for service industry firms than that of manufacturing industry firms.

\section{Conclusion}

In this paper, I use monthly data to provide empirical evidence on the relation between stock returns and inflationary expectations using a panel of one hundred and seventy firms covering a broad range of industries and Turkish common stock market index from 1986 to 2013 during which monetary regime shifts occurred. Using aggregate (common stock market) and disaggregate, (both company and industry level) data, along with survey of inflationary expectations, I provide empirical evidence that stock returns provide a good hedge against ex-ante inflationary expectations but not ex-post realized expected inflation. The results are robust to use of common stock market returns vs. returns at disaggregated level. I find statistically different estimates of Fisher effect for firms operating under manufacturing than that of service industries. Point estimates of Fisher elasticities of stock prices with respect to manufacturing goods prices and service goods are 1.89 and 1.63 , respectively i.e. holding stocks of manufacturing industry firms provide a better hedge for about $15 \%$ in comparison to that of service industry firms. Using sub-periods of data identified by structural break optimization procedure does not seem to provide any statistically different estimates of the Fisher effect. 


\section{References}

Bai, J., \& Perron, P. (1998) Estimating and testing linear models with multiple structural changes. Econometrica, 66, 47-78.

Bai, J., \& Perron, P. (2003) Computation and analysis of multiple structural change models. Journal of Applied Econometrics, 18, 1-22.

Bodie, Z. (1976) Common stocks as a hedge against inflation. The Journal of Finance, $31,459-470$.

Clemente, J., Montanés, A., \& Reyes, M. (1998) Testing for a unit root in variables with a double change in the mean. Economic Letters, 59, 175-182.

Crowder, W. J., \& Hoffman, D. L. (1996) The Long-run relationship between nominal interest rates and inflation: the Fisher equation revisited. Journal of Money, Credit and Banking, 28, 102-118.

Elliott, G., Rothenberg, T. J., \& Stock, J. H. (1996) Efficient tests for an autoregressive unit root. Econometrica, 64, 813-836.

Ely, D. P., \& Robinson, K. J. (1997) Are stocks a hedge against inflation? International evidence using a long-run approach. Journal of International Money and Finance, 16, 141-167.

Fama, E. F., \& Schwert, G. W. (1977) Asset returns and inflation. Journal of Financial Economics, 5, 115-146.

Fisher, I. (1930) The theory of interest as determined by impatience to spend income and opportunity to invest it. New York: The Macmillan Co.

Geske, R., \& Roll, R. (1983) The fiscal and monetary linkage between stock returns and inflation. The Journal of Finance, 38, 1-33.

Gultekin, N. B. (1983) Stock market returns and inflation forecasts. The Journal of Finance, 38, 663-673.

Gül, E., \& Açıkalın, S. (2008) An examination of the Fisher hypothesis: the case of Turkey. Applied Economics, 40, 3227-3231.

Hodrick, R. J., \& Prescott E. C. (1997) Postwar U.S. business cycles: an empirical investigation. Journal of Money, Credit and Banking, 29, 1-16.

İncekara, A., Demez, S., \& Ustaoğlu, M. (2012) Validity of Fisher effect for Turkish economy: conintegration analysis. Procedia - Social and behavioral Sciences, $58,396-405$. 
Kolari, J. W., \& Anari, A. (2001) Stock prices and inflation. Journal of Financial Research, 24, 587-602.

Lee, B. S. (2010) Stock returns and inflation revisited: An evaluation of the inflation illusion hypothesis. Journal of Banking and Finance, 6, 1257-1273.

Lee, S. R., Tang, D. P., \& Wong K. M. (2000) Stock returns during the German hyperinflation, Quarterly review of Economics and Finance, 3, 375-386.

Liu, J., Wu, S., \& Zidek, J. V. (1997) On segmented multivariate regression.

Statistica Sinica, 7, 497-525.

Luintel, K. B., \& Paudyal, K. (2006) Are common stocks a hedge against inflation. Journal of Financial Research, 29, 1-19.

Nelson, C. (1976) Inflation and rates of return on common stocks. The Journal of Finance, 31, 471-483.

Paseran, M. H., Shin, Y., \& Smith, R. (2001) Bound testing approaches to the analysis of level relationships. Journal of Applied Econometrics, 16, 289-326.

Solnik, B. (1983) The relation between stock prices and inflationary expectations: the international evidence. The Journal of Finance, 38, 35-48.

Stock, J. H., \& Yogo, M. (2005) Testing for weak instruments in linear IV regression. In D. W. K. Andrews \& J. H. Stock (Eds.) Identification and Inference for Econometric Models: Essays in Honor of Thomas Rothenberg (pp. 80-108). Cambridge: Cambridge University Press.

Şimşek, M., \& Kadılar, C. (2006) Fisher etkisinin Türkiye verileri ile testi. Doğuş Üniversitesi Dergisi, 7, 99-111.

Turgutlu, E. (2004) Fisher hipotezinin tutarlılığının testi: parçalı durağanlık ve parçalı koentegrasyon analizi. Dokuz Eylül Üniversitesi IIBF Dergisi, 19, 55-74.

Yasser, A. F. F., \& Magda, K. (2003) The Fisher effect: new evidence and implications. International Review of Economics and Finance, 12, 451-465. 


\section{Additional Table and Figures}

Table 1. Company \& Industry levels descriptive statistics

\begin{tabular}{|c|c|c|c|c|c|c|}
\hline ID & Sector Name & $\begin{array}{l}\text { Number of } \\
\text { Companies }\end{array}$ & $\begin{array}{l}1986 \mathrm{~m} 1- \\
2013 \mathrm{~m} 6\end{array}$ & $\begin{array}{c}1986 \mathrm{~m} 1- \\
1994 \mathrm{~m} 3\end{array}$ & $\begin{array}{l}1994 \mathrm{~m} 4- \\
2003 \mathrm{~m} 11\end{array}$ & $\begin{array}{c}2003 \mathrm{~m} 12- \\
2013 \mathrm{~m} 6\end{array}$ \\
\hline 1 & Banks and Special Financial Corporations & 14 & $\begin{array}{l}0.2399 \\
(4620)\end{array}$ & $\begin{array}{c}-3.9464 \\
(2688)\end{array}$ & $\begin{array}{c}-12.3653 \\
(1624)\end{array}$ & $\begin{array}{l}5.2588 \\
(1610)\end{array}$ \\
\hline 2 & Basic Metal Industries & 6 & $\begin{array}{l}2.0729 \\
(1980)\end{array}$ & $\begin{array}{l}2.7509 \\
(1152)\end{array}$ & $\begin{array}{c}-2.0831 \\
(696)\end{array}$ & $\begin{array}{c}0.2934 \\
(690)\end{array}$ \\
\hline 3 & Chemicals, Petroleum Rubber and Plastic Products & 16 & $\begin{array}{l}1.7299 \\
(5280)\end{array}$ & $\begin{array}{l}4.5297 \\
(3072)\end{array}$ & $\begin{array}{c}-2.5896 \\
(1856)\end{array}$ & $\begin{array}{l}2.4245 \\
(1840)\end{array}$ \\
\hline 4 & Construction and Public Works & 1 & $\begin{array}{c}-24.3562 \\
(330)\end{array}$ & $\begin{array}{l}-- \\
--\end{array}$ & $\begin{array}{c}-44.9136 \\
(116)\end{array}$ & $\begin{array}{c}-23.4624 \\
(115)\end{array}$ \\
\hline 5 & Consumer Trade & 5 & $\begin{array}{c}-5.6429 \\
(1650)\end{array}$ & $\begin{array}{c}-27.8090 \\
(960)\end{array}$ & $\begin{array}{c}-22.6691 \\
(580)\end{array}$ & $\begin{array}{c}3.3087 \\
(575)\end{array}$ \\
\hline 6 & Crude Petroleum and Natural Gas Production & 1 & $\begin{array}{c}-3.4942 \\
(330)\end{array}$ & $\begin{array}{c}-210.2816 \\
(192)\end{array}$ & $\begin{array}{c}-80.9357 \\
(116)\end{array}$ & $\begin{array}{c}16.7079 \\
(115)\end{array}$ \\
\hline 7 & Defense & 1 & $\begin{array}{c}4.7554 \\
(330)\end{array}$ & $\begin{array}{c}12.1739 \\
(192)\end{array}$ & $\begin{array}{c}6.4462 \\
(116)\end{array}$ & $\begin{array}{c}-2.5872 \\
(115)\end{array}$ \\
\hline 8 & Education, Health, Sports and Other Social Services & 5 & $\begin{array}{l}1.2543 \\
(1650)\end{array}$ & $\begin{array}{l}-- \\
--\end{array}$ & $\begin{array}{c}-13.2715 \\
(580)\end{array}$ & $\begin{array}{c}1.8228 \\
(575)\end{array}$ \\
\hline 9 & Electricity Gas and Steam & 4 & $\begin{array}{c}-22.3553 \\
(1320)\end{array}$ & $\begin{array}{c}-30.3836 \\
(768)\end{array}$ & $\begin{array}{c}-60.8792 \\
(464)\end{array}$ & $\begin{array}{c}-13.1137 \\
(460)\end{array}$ \\
\hline 10 & Fabricated Metal Products, Machinery and Equipment & 18 & $\begin{array}{c}-0.4375 \\
(5940)\end{array}$ & $\begin{array}{c}3.18916 \\
(3456)\end{array}$ & $\begin{array}{c}-4.6118 \\
(2088)\end{array}$ & $\begin{array}{c}-1.9009 \\
(2070)\end{array}$ \\
\hline 11 & Financial Leasing and Factoring Companies & 1 & $\begin{array}{c}-14.7567 \\
(330)\end{array}$ & $\begin{array}{c}-114.8150 \\
(192)\end{array}$ & $\begin{array}{c}-60.3686 \\
(116)\end{array}$ & $\begin{array}{c}-1.6680 \\
(115)\end{array}$ \\
\hline 12 & Food, Beverage and Tobacco & 12 & $\begin{array}{c}-5.8280 \\
(3960)\end{array}$ & $\begin{array}{c}-21.8933 \\
(2304)\end{array}$ & $\begin{array}{c}-26.2013 \\
(1392)\end{array}$ & $\begin{array}{l}3.5212 \\
(1380)\end{array}$ \\
\hline 13 & Holding and Investment Companies & 21 & $\begin{array}{c}-5.8684 \\
(6930)\end{array}$ & $\begin{array}{c}-2.7302 \\
(4032)\end{array}$ & $\begin{array}{c}-14.0433 \\
(2436)\end{array}$ & $\begin{array}{c}-2.6908 \\
(2415)\end{array}$ \\
\hline 14 & Information Technology & 6 & -7.3816 & 6.1736 & -13.0865 & -7.1777 \\
\hline
\end{tabular}




\begin{tabular}{|c|c|c|c|c|c|c|}
\hline 15 & Insurance Companies & 5 & $\begin{array}{c}(1980) \\
-7.1084 \\
(1650)\end{array}$ & $\begin{array}{c}(1152) \\
-23.1513 \\
(960)\end{array}$ & $\begin{array}{c}(696) \\
-24.7194 \\
(580)\end{array}$ & $\begin{array}{c}(690) \\
6.1840 \\
(575)\end{array}$ \\
\hline 16 & Mining & 3 & $\begin{array}{c}4.3024 \\
(990)\end{array}$ & $\begin{array}{c}-0.0707 \\
(576)\end{array}$ & $\begin{array}{c}-2.4099 \\
(348)\end{array}$ & $\begin{array}{c}5.9217 \\
(345)\end{array}$ \\
\hline 17 & Non-Metallic Mineral Products & 15 & $\begin{array}{l}-.9554 \\
(4950)\end{array}$ & $\begin{array}{c}-3.5516 \\
(2880)\end{array}$ & $\begin{array}{c}-7.4183 \\
(1740)\end{array}$ & $\begin{array}{l}2.4280 \\
(1725)\end{array}$ \\
\hline 18 & Other Manufacturing Industry & 2 & $\begin{array}{c}-2.1595 \\
(660)\end{array}$ & $\begin{array}{c}-19.7767 \\
(384)\end{array}$ & $\begin{array}{c}-13.2931 \\
(232)\end{array}$ & $\begin{array}{c}4.1334 \\
(230)\end{array}$ \\
\hline 19 & Paper and Paper Products, Printing and Publishing & 6 & $\begin{array}{c}-0.9929 \\
(1980)\end{array}$ & $\begin{array}{c}-1.1121 \\
(1152)\end{array}$ & $\begin{array}{c}-5.8588 \\
(696)\end{array}$ & $\begin{array}{c}-4.5709 \\
(690)\end{array}$ \\
\hline 20 & Real Estate Investment Trusts & 6 & $\begin{array}{r}-1.4200 \\
(1980)\end{array}$ & $\begin{array}{c}-1.4831 \\
(1152)\end{array}$ & $\begin{array}{c}-20.7148 \\
(696)\end{array}$ & $\begin{array}{c}3.7627 \\
(690)\end{array}$ \\
\hline 21 & Restaurants and Hotels & 4 & $\begin{array}{c}-13.4469 \\
(1320)\end{array}$ & $\begin{array}{c}-13.4408 \\
(768)\end{array}$ & $\begin{array}{c}-22.9382 \\
(464)\end{array}$ & $\begin{array}{c}-8.3761 \\
(460)\end{array}$ \\
\hline 22 & Telecommunication & 2 & $\begin{array}{c}-0.3930 \\
(660)\end{array}$ & $\begin{array}{c}-143.4821 \\
(384)\end{array}$ & $\begin{array}{c}-32.7231 \\
(232)\end{array}$ & $\begin{array}{c}5.2892 \\
(230)\end{array}$ \\
\hline 23 & Textile, Wearing Apparel and Leather & 10 & $\begin{array}{l}-8.3922 \\
(3300)\end{array}$ & $\begin{array}{c}-14.9458 \\
(1920)\end{array}$ & $\begin{array}{c}-19.6048 \\
(1160)\end{array}$ & $\begin{array}{r}-2.1277 \\
(1150)\end{array}$ \\
\hline 24 & Transportation & 2 & $\begin{array}{c}0.4643 \\
(660)\end{array}$ & $\begin{array}{l}8.5418 \\
(384)\end{array}$ & $\begin{array}{c}-3.1716 \\
(232)\end{array}$ & $\begin{array}{c}0.2944 \\
(230)\end{array}$ \\
\hline 25 & Wholesale Trade & 3 & $\begin{array}{c}-3.4935 \\
(990)\end{array}$ & $\begin{array}{c}-116.3614 \\
(576)\end{array}$ & $\begin{array}{c}-8.7352 \\
(348)\end{array}$ & $\begin{array}{c}-3.0186 \\
345\end{array}$ \\
\hline 26 & Wood Products including Furniture & 1 & $\begin{array}{c}-7.5915 \\
(330)\end{array}$ & $\begin{array}{c}-4.1290 \\
(192)\end{array}$ & $\begin{array}{c}-17.3721 \\
(116)\end{array}$ & $\begin{array}{c}-1.8053 \\
(115)\end{array}$ \\
\hline & Weighted Average & & -3.31 & 15.34 & -13.65 & 0.11 \\
\hline & Total & 170 & $(56,100)$ & $(31,488)$ & $(19720)$ & $(18860)$ \\
\hline & ISE100 & 100 & 41.27 & 63.65 & 46.25 & 19.51 \\
\hline
\end{tabular}

Notes: The data has monthly frequency covering the period from January 1986 to June 2013. This table shows nominal mean values of sectorial stock returns. Values in parenthesis are the frequencies. 
Table 2. ISE100 companies during 2000-2013

\begin{tabular}{|c|c|c|c|c|c|c|c|c|c|c|c|c|c|c|c|c|c|c|c|}
\hline 2000 & 2001 & 2002 & 2003 & 2004 & 2005 & 2006 & 2007 & 2008 & 2009 & 2010 & 2011 & 2012 & 2013 & ISE Ticker & Sector ID & $\begin{array}{c}\text { Total } \\
\text { Assets } \\
\end{array}$ & Net Sales & $\begin{array}{c}\text { Net } \\
\text { Profits }\end{array}$ & $\begin{array}{c}\text { Market } \\
\text { Value }\end{array}$ \\
\hline ISE30 & ISE30 & ISE30 & ISE30 & ISE30 & ISE30 & ISE30 & ISE30 & ISE30 & ISE30 & ISE30 & ISE30 & ISE30 & ISE30 & AKBNK & 1 & -- & -- & $1,682.5$ & $20,700.0$ \\
\hline-- & -- & -- & -- & -- & -- & -- & -- & ISE50 & ISE50 & ISE100 & ISE100 & -- & ISE100 & ALBRK & 1 & -- & -- & 138.9 & 867.8 \\
\hline-- & -- & -- & -- & -- & -- & -- & ISE30 & ISE30 & ISE30 & ISE30 & ISE30 & ISE30 & ISE30 & ASYAB & 1 & -- & -- & 261.8 & $1,926.0$ \\
\hline -- & -- & -- & -- & -- & ISE30 & ISE30 & ISE30 & ISE100 & -- & ISE100 & -- & -- & -- & DENIZ & 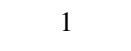 & -- & -- & 331.4 & $5,549.8$ \\
\hline ISE30 & ISE50 & ISE50 & ISE30 & ISE30 & ISE30 & ISE30 & ISE30 & ISE100 & ISE100 & -- & -- & ISE30 & -- & FINBN & 1 & -- & -- & 583.9 &, 725.0 \\
\hline ISE30 & ISE30 & ISE30 & ISE30 & ISE30 & ISE30 & ISE30 & ISE30 & ISE30 & ISE30 & ISE30 & ISE30 & ISE30 & ISE30 & GARAN & 1 & -- & -- & $1,947.9$ & 17,556 \\
\hline-- & -- & -- & -- & -- & -- & -- & ISE30 & ISE30 & ISE30 & ISE30 & ISE30 & ISE30 & ISE30 & HALKB & 1 & -- & -- & $1,082.5$ & ,625.0 \\
\hline ISE30 & ISE30 & ISE30 & ISE30 & ISE30 & ISE30 & ISE30 & ISE30 & ISE30 & ISE30 & ISE30 & ISE30 & ISE30 & ISE30 & ISCTR & 1 & -- & -- & $13,981.4$ & $1,560.0$ \\
\hline-- & -- & -- & ISE30 & ISE100 & ISE30 & ISE30 & ISE30 & ISE30 & ISE30 & ISE30 & ISE50 & ISE100 & ISE100 & SKBNK & 1 & -- & -- & 126.9 & 805.0 \\
\hline ISE100 & ISE50 & ISE50 & ISE50 & ISE100 & ISE100 & ISE100 & ISE100 & ISE50 & ISE30 & ISE30 & ISE30 & -- & ISE100 & TEBNK & 1 & -- & -- & 32.6 & 787.2 \\
\hline -- & -- & -- & -- & -- & ISE100 & ISE100 & ISE100 & ISE100 & ISE100 & ISE100 & ISE100 & ISE100 & ISE100 & TEKST & . & -- & -- & 13 & 352.8 \\
\hline-- & -- & ISE100 & ISE100 & -- & ISE50 & ISE30 & ISE30 & ISE30 & ISE30 & ISE50 & ISE50 & ISE100 & ISE50 & TSKB & 1 & -- & -- & 124.5 & 540.0 \\
\hline-- & -- & -- & -- & -- & -- & ISE30 & ISE30 & ISE30 & ISE30 & ISE30 & ISE30 & ISE30 & ISE30 & VAKBN & 1 & -- & -- & 851.0 & 5,825 \\
\hline ISE30 & ISE30 & ISE30 & ISE30 & ISE30 & ISE30 & ISE30 & ISE30 & ISE30 & ISE30 & ISE30 & ISE30 & ISE30 & ISE30 & YKBNK & 1 & -- & -- & $1,037.6$ & $9,911.2$ \\
\hline-- & ISE100 & -- & ISE100 & ISE100 & ISE100 & -- & -- & -- & -- & -- & -- & ISE100 & ISE100 & BRSAN & 2 & $2,248.0$ & $11,596.5$ & -376.6 & $2,140.4$ \\
\hline ISE30 & ISE30 & ISE30 & ISE30 & ISE30 & ISE30 & ISE30 & ISE30 & ISE30 & ISE30 & ISE30 & ISE30 & ISE30 & ISE30 & EREGL & 2 & $61,036.3$ & $68,086.9$ & $2,114.7$ & $47,331.1$ \\
\hline ISE100 & ISE100 & ISE100 & ISE50 & ISE50 & ISE50 & ISE30 & ISE30 & ISE100 & ISE100 & ISE100 & ISE100 & ISE50 & ISE50 & IZMDC & 2 & $3,927.7$ & $13,976.7$ & $1,315.9$ & $3,137.4$ \\
\hline-- & -- & -- & ISE100 & ISE30 & -- & ISE100 & -- & -- & -- & -- & -- & ISE50 & ISE50 & KRDMA & 2 & $5526.3^{*}$ & $11018.9^{*}$ & $827.9^{*}$ & $5071.2 *$ \\
\hline ISE50 & ISE50 & ISE100 & ISE50 & ISE30 & ISE30 & ISE50 & ISE30 & ISE30 & ISE30 & ISE30 & ISE30 & ISE30 & ISE30 & KRDMD & 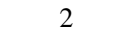 & $5526.3^{*}$ & $11018.9^{*}$ & $827.9^{*}$ & $5071.2 *$ \\
\hline ISE100 & ISE100 & -- & -- & ISE50 & -- & -- & ISE30 & ISE100 & ISE100 & -- & ISE100 & ISE100 & ISE50 & SARKY & 2 & $2,070.6$ & $17,827.6$ & 6.2 & $1,020.0$ \\
\hline ISE50 & ISE50 & ISE30 & ISE30 & ISE30 & ISE30 & ISE50 & ISE50 & ISE100 & ISE100 & ISE100 & ISE50 & ISE30 & ISE50 & AKSA & 8 & $7,132.1$ & $9,084.6$ & 729.1 & $2,398.0$ \\
\hline ISE30 & ISE100 & ISE100 & ISE100 & ISE100 & ISE100 & -- & -- & ISE50 & ISE50 & ISE100 & -- & ISE100 & ISE100 & ALKIM & 3 & $1,451.3$ & $1,478.5$ & 223.6 & $1,335.2$ \\
\hline ISE50 & ISE50 & ISE50 & ISE50 & ISE50 & ISE50 & ISE50 & ISE30 & ISE30 & ISE50 & ISE50 & ISE100 & ISE50 & ISE50 & AYGAZ & 5 & $14,736.9$ & $35,792.9$ & 257.7 & $9,720.0$ \\
\hline ISE30 & ISE30 & ISE30 & ISE100 & -- & ISE100 & ISE100 & ISE100 & ISE50 & ISE30 & ISE50 & ISE50 & ISE50 & ISE50 & BAGFS & 3 & $1,825.9$ & $3,902.5$ & 827.7 & $2,130.0$ \\
\hline ISE100 & ISE50 & ISE100 & -- & -- & ISE30 & ISE100 & -- & -- & -- & -- & ISE30 & ISE50 & ISE100 & BRISA & 3 & $4,173.1$ & $7,722.0$ & 318.0 & $2,883.7$ \\
\hline ISE100 & ISE100 & ISE100 & ISE100 & ISE100 & ISE100 & ISE30 & ISE100 & ISE30 & -- & ISE100 & ISE100 & ISE100 & -- & DEVA & 3 & -- & -- & -65.5 & 527 \\
\hline-- & -- & -- & -- & -- & -- & -- & -- & -- & ISE100 & ISE100 & ISE100 & ISE100 & ISE100 & EGGUB & 3 & $1,080.9$ & $2,049.5$ & 39.0 & 577.5 \\
\hline-- & -- & -- & -- & -- & ISE100 & ISE100 & ISE100 & -- & -- & -- & ISE100 & ISE50 & ISE100 & GOODY & 3 & $2,637.5$ & $7,652.0$ & 77.1 & $1,078.5$ \\
\hline
\end{tabular}




\begin{tabular}{|c|c|c|c|c|c|c|c|c|c|c|c|c|c|c|}
\hline-- & -- & -- & -- & -- & -- & -- & -- & ISE50 & ISE50 & ISE100 & ISE50 & ISE50 & ISE50 & GUBRF \\
\hline -- & ISE100 & ISE100 & ISE100 & ISE100 & ISE100 & -- & -- & -- & -- & -- & -- & -- & -- & HEKTS \\
\hline E30 & ISE30 & ISE30 & ISE30 & ISE50 & ISE30 & ISE30 & ISE30 & ISE30 & ISE30 & ISE30 & ISE30 & ISE30 & ISE30 & РETKM \\
\hline- & ISE100 & -- & -- & ISE100 & ISE100 & -- & ISE30 & -- & -- & -- & ISE50 & -- & ISE30 & PIMAS \\
\hline E30 & ISE30 & ISE30 & ISE30 & ISE30 & ISE30 & ISE30 & ISE30 & ISE30 & ISE50 & ISE50 & ISE50 & ISE100 & ISE30 & PTOFS \\
\hline$E 100$ & ISE100 & ISE100 & ISE100 & ISE100 & ISE100 & ISE100 & ISE100 & ISE100 & ISE100 & ISE100 & ISE100 & ISE30 & ISE100 & SASA \\
\hline SE100 & ISE100 & ISE100 & ISE100 & ISE100 & ISE100 & ISE100 & ISE50 & ISE100 & ISE50 & ISE50 & -- & ISE100 & ISE100 & TRCAS \\
\hline E30 & ISE30 & ISE30 & ISE30 & ISE30 & ISE30 & ISE30 & ISE30 & ISE30 & ISE30 & ISE30 & ISE30 & ISE30 & ISE30 & TUPRS \\
\hline-- & -- & ISE30 & ISE30 & ISE30 & ISE30 & ISE50 & ISE50 & ISE50 & ISE30 & ISE30 & ISE30 & ISE30 & ISE30 & ENKAI \\
\hline-- & -- & -- & -- & -- & ISE50 & ISE100 & -- & ISE50 & ISE30 & ISE30 & ISE50 & ISE30 & ISE30 & BIMAS \\
\hline -- & -- & -- & -- & -- & ISE100 & ISE100 & ISE100 & ISE100 & ISE100 & -- & ISE100 & ISE30 & ISE100 & BOYNR \\
\hline E50 & ISE50 & ISE50 & ISE50 & ISE50 & -- & -- & -- & ISE100 & ISE30 & ISE100 & ISE100 & -- & ISE100 & KIPA \\
\hline- & -- & -- & -- & -- & -- & -- & -- & -- & ISE100 & ISE100 & ISE100 & ISE30 & ISE30 & MGROS \\
\hline E50 & ISE100 & ISE100 & ISE30 & ISE100 & ISE30 & -- & ISE50 & -- & ISE100 & -- & -- & -- & ISE100 & MIPAZ \\
\hline-- & -- & -- & -- & -- & -- & -- & -- & -- & -- & -- & ISE50 & ISE30 & ISE30 & IPEKE \\
\hline E50 & ISE50 & ISE50 & ISE50 & ISE30 & ISE50 & ISE30 & ISE100 & ISE100 & ISE100 & ISE100 & ISE50 & ISE50 & ISE30 & ASELS \\
\hline-- & -- & -- & -- & -- & -- & ISE30 & ISE30 & -- & ISE100 & -- & ISE50 & ISE100 & -- & AFMAS \\
\hline- & -- & -- & -- & ISE100 & -- & -- & -- & -- & -- & ISE30 & ISE100 & ISE100 & ISE100 & BJKAS \\
\hline & -- & -- & -- & ISE50 & ISE100 & ISE100 & ISE100 & -- & ISE100 & ISE100 & ISE30 & ISE50 & ISE50 & FENER \\
\hline & -- & ISE100 & ISE100 & -- & -- & -- & -- & -- & -- & ISE100 & ISE100 & ISE50 & ISE50 & GSRAY \\
\hline & -- & -- & -- & -- & -- & -- & -- & -- & -- & -- & ISE100 & ISE100 & ISE100 & TSPOR \\
\hline & ISE30 & ISE30 & ISE30 & ISE30 & ISE50 & ISE50 & ISE100 & ISE50 & ISE50 & ISE50 & ISE30 & ISE50 & ISE30 & AKENR \\
\hline & -- & -- & -- & -- & -- & -- & -- & -- & -- & -- & ISE100 & ISE100 & ISE50 & AKSEN \\
\hline 10 & ISE50 & ISE50 & ISE100 & -- & ISE100 & ISE100 & ISE100 & -- & -- & -- & ISE100 & -- & -- & AYEN \\
\hline-- & ISE50 & ISE50 & ISE100 & ISE100 & ISE100 & ISE100 & ISE100 & ISE100 & ISE100 & ISE50 & ISE100 & ISE100 & ISE100 & ZOREN \\
\hline E30 & ISE30 & ISE30 & ISE30 & ISE30 & ISE30 & ISE50 & ISE30 & ISE50 & ISE100 & ISE100 & ISE100 & ISE100 & ISE100 & ALARK \\
\hline E30 & ISE30 & ISE30 & ISE30 & ISE30 & ISE30 & ISE30 & ISE30 & ISE30 & ISE50 & ISE30 & ISE30 & ISE30 & ISE30 & ARCLK \\
\hline E100 & ISE100 & ISE100 & ISE100 & ISE100 & -- & ISE100 & -- & -- & ISE30 & -- & ISE100 & ISE50 & ISE100 & ASUZU \\
\hline SE30 & -- & -- & ISE50 & -- & ISE100 & ISE100 & -- & ISE100 & -- & -- & -- & -- & -- & BFREN \\
\hline-- & -- & ISE50 & -- & -- & ISE100 & ISE30 & ISE30 & ISE30 & -- & ISE100 & -- & ISE100 & ISE50 & FMIZP \\
\hline 230 & ISE30 & ISE30 & ISE30 & ISE30 & ISE30 & ISE30 & ISE50 & ISE50 & ISE100 & ISE50 & ISE50 & ISE30 & ISE50 & FROTO \\
\hline & -- & -- & ISE50 & ISE50 & ISE100 & -- & -- & ISE100 & ISE100 & ISE50 & ISE100 & ISE100 & ISE100 & IHEVA \\
\hline 50 & ISE100 & ISE100 & -- & ISE100 & ISE30 & ISE50 & ISE50 & ISE50 & ISE100 & ISE100 & ISE30 & ISE100 & ISE100 & KARSN \\
\hline
\end{tabular}

\begin{tabular}{|rrrr}
$7,299.2$ & $14,116.5$ & $1,033.4$ & $6,304.3$ \\
-- & - & 8.0 & 62.2 \\
$13,565.9$ & $23,204.3$ & $-1,512.6$ & $12,285.0$ \\
-- & -- & -10.8 & 99.9 \\
$27,579.9$ & $172,021.7$ & $1,054.7$ & $27,170.0$ \\
$2,370.0$ & $3,543.9$ & -507.0 & 908.5 \\
-- & -- & -20.4 & 546 \\
$35,562.6$ & $304,564.0$ & $4,322.2$ & $48,080.5$ \\
$53,287.3$ & $91,318.9$ & $7,708.3$ & $85,320.0$ \\
$2,661.0$ & $42,424.1$ & $1,141.8$ & $34,914.0$ \\
514.0 & $4,564.8$ & 4.0 & 791.8 \\
$5,691.9$ & $11,573.5$ & -739.7 & $6,596.8$ \\
$16,243.8$ & $50,737.5$ & $2,614.8$ & $33,825.7$ \\
-- & -- & -7.0 & 32.5 \\
-- & -- & -- & -- \\
$4,844.8$ & $7,059.0$ & 121.9 & $4,798.6$ \\
-- & -- & -10.6 & 129.5 \\
140.3 & 947.2 & -13.5 & $2,240.0$ \\
-- & -- & 72.1 & 1,300 \\
-- & -- & 81.6 & 248.2 \\
-- & -- & 29.8 & 202.5 \\
-- & -- & 63.7 & 653.4 \\
-- & -- & -- & -- \\
$2,410.3$ & $1,006.7$ & 417.2 & $2,475.9$ \\
-3.7 & $6,670.3$ & $-3,362.5$ & $2,891.0$ \\
-- & -- & 68.8 & 621.7 \\
$20,013.3$ & $67,755.4$ & 397.9 & $15,178.5$ \\
$1,854.8$ & $4,967.6$ & -4.7 & $1,235.4$ \\
101.4 & $1,430.9$ & -135.2 & $1,950.0$ \\
-- & -- & 14.4 & 147.0 \\
$17,117.6$ & $70,068.7$ & $4,362.0$ & $22,107.3$ \\
-- & -- & -14.5 & 158.8 \\
648.1 & $2,064.6$ & -433.9 & $1,270.0$ \\
& & &
\end{tabular}




\begin{tabular}{|c|c|c|c|c|c|c|c|c|c|c|c|c|c|c|}
\hline ISE30 & -- & -- & -- & -- & ISE100 & ISE50 & -- & ISE30 & -- & ISE50 & ISE100 & -- & ISE50 & KLMSN \\
\hline-- & -- & ISE100 & -- & -- & ISE30 & -- & -- & ISE30 & ISE100 & -- & ISE30 & ISE100 & ISE100 & MUTLU \\
\hline ISE50 & ISE50 & ISE100 & ISE100 & ISE100 & ISE100 & ISE100 & ISE100 & ISE100 & ISE100 & ISE100 & -- & ISE100 & ISE50 & OTKAR \\
\hline ISE100 & -- & ISE100 & -- & -- & -- & ISE50 & -- & -- & ISE30 & -- & -- & -- & -- & PARSN \\
\hline-- & -- & -- & -- & -- & -- & -- & ISE30 & ISE30 & ISE30 & -- & ISE30 & ISE50 & -- & SILVR \\
\hline ISE30 & ISE30 & ISE30 & ISE30 & ISE30 & ISE30 & ISE30 & ISE30 & ISE50 & ISE30 & ISE30 & ISE50 & ISE30 & ISE30 & TOASO \\
\hline-- & -- & -- & -- & -- & ISE50 & ISE50 & ISE100 & -- & -- & ISE100 & ISE100 & ISE30 & ISE30 & TTRAK \\
\hline ISE100 & ISE100 & ISE100 & ISE100 & ISE100 & ISE100 & ISE100 & ISE100 & ISE100 & -- & -- & -- & -- & -- & TUDDF \\
\hline-- & -- & - & -- & -- & -- & -- & ISE50 & ISE50 & ISE50 & ISE100 & -- & -- & -- & VESBE \\
\hline ISE30 & ISE30 & ISE30 & ISE30 & ISE30 & ISE30 & ISE30 & ISE30 & ISE50 & ISE50 & ISE30 & ISE50 & ISE100 & ISE100 & VESTL \\
\hline-- & -- & -- & -- & ISE100 & ISE100 & ISE50 & ISE100 & ISE100 & ISE100 & ISE100 & ISE100 & ISE100 & ISE50 & ISFIN \\
\hline-- & ISE30 & ISE30 & ISE30 & ISE50 & ISE30 & ISE50 & ISE50 & ISE50 & ISE30 & ISE30 & ISE50 & ISE50 & ISE50 & AEFES \\
\hline ISE100 & ISE100 & ISE100 & ISE100 & ISE50 & ISE100 & ISE30 & ISE100 & ISE100 & ISE30 & ISE100 & ISE100 & ISE100 & ISE100 & BANVT \\
\hline-- & -- & -- & -- & -- & -- & -- & ISE50 & ISE100 & ISE50 & ISE100 & -- & ISE100 & ISE50 & CCOLA \\
\hline ISE100 & ISE100 & ISE100 & ISE30 & -- & ISE100 & ISE100 & ISE100 & -- & ISE30 & -- & -- & ISE50 & -- & DARDL \\
\hline-- & ISE100 & ISE30 & -- & ISE30 & ISE30 & -- & ISE30 & -- & -- & -- & -- & ISE50 & -- & KNFRT \\
\hline-- & ISE30 & ISE50 & -- & -- & -- & -- & ISE100 & ISE30 & ISE100 & ISE30 & -- & ISE100 & ISE100 & MERKO \\
\hline ISE100 & ISE100 & ISE100 & ISE100 & ISE30 & -- & -- & -- & ISE100 & -- & -- & ISE50 & -- & -- & PENGD \\
\hline ISE100 & ISE50 & -- & -- & -- & ISE100 & -- & ISE100 & ISE100 & -- & ISE100 & -- & -- & -- & PETUN \\
\hline ISE100 & -- & -- & -- & -- & ISE100 & ISE100 & ISE100 & ISE100 & -- & ISE100 & -- & -- & -- & PNSUT \\
\hline ISE30 & -- & -- & -- & -- & -- & -- & ISE100 & ISE30 & ISE30 & -- & -- & ISE50 & ISE100 & SELGD \\
\hline ISE100 & ISE100 & ISE100 & ISE100 & ISE100 & ISE50 & ISE50 & ISE100 & ISE100 & ISE100 & ISE100 & ISE100 & -- & -- & TATKS \\
\hline-- & -- & -- & -- & ISE30 & ISE30 & ISE30 & ISE30 & ISE30 & ISE50 & ISE50 & ISE50 & ISE100 & ISE100 & ULKER \\
\hline ISE100 & ISE100 & -- & -- & -- & ISE100 & -- & ISE30 & -- & -- & ISE100 & -- & -- & ISE30 & ALCAR \\
\hline-- & -- & ISE30 & ISE100 & ISE100 & ISE30 & ISE30 & -- & -- & -- & -- & ISE100 & ISE30 & ISE50 & ATSYO \\
\hline-- & -- & -- & -- & ISE30 & -- & ISE100 & ISE50 & -- & ISE100 & -- & -- & -- & ISE100 & AVRSY \\
\hline ISE100 & ISE100 & ISE100 & ISE100 & ISE100 & ISE100 & ISE100 & -- & -- & -- & -- & -- & -- & -- & BRYAT \\
\hline ISE30 & ISE30 & ISE30 & ISE30 & ISE30 & ISE30 & ISE30 & ISE30 & ISE30 & ISE30 & ISE30 & ISE30 & ISE30 & ISE30 & DOHOL \\
\hline ISE30 & ISE30 & ISE30 & ISE30 & ISE30 & ISE30 & ISE30 & ISE30 & ISE30 & ISE30 & ISE30 & ISE30 & ISE50 & ISE50 & DYHOL \\
\hline ISE50 & ISE50 & ISE100 & ISE50 & ISE50 & ISE50 & ISE50 & ISE30 & ISE30 & ISE50 & ISE30 & ISE30 & ISE50 & ISE50 & ECILC \\
\hline ISE50 & ISE50 & ISE50 & ISE50 & ISE100 & ISE100 & ISE100 & ISE100 & ISE100 & ISE100 & ISE100 & ISE100 & ISE100 & ISE100 & ECZYT \\
\hline-- & -- & -- & -- & -- & ISE50 & ISE30 & ISE50 & ISE30 & ISE30 & ISE100 & ISE50 & ISE100 & ISE100 & GLYHO \\
\hline ISE100 & ISE100 & ISE50 & ISE50 & ISE50 & ISE50 & ISE30 & ISE30 & ISE30 & ISE50 & ISE50 & ISE50 & ISE100 & ISE100 & GSDHO \\
\hline
\end{tabular}

\begin{tabular}{|rrrr}
260.3 & 999.8 & -50.6 & 885.0 \\
$1,112.2$ & $3,031.7$ & 10.4 & 788.1 \\
$1,479.0$ & $4,791.1$ & 348.6 & $3,072.0$ \\
$2,339.5$ & $1,478.1$ & 204.6 & 809.7 \\
-- & -- & -1.4 & 26.1 \\
$11,194.6$ & $47,980.3$ & $1,757.5$ & $13,900.0$ \\
$2,855.5$ & $7,874.9$ & 667.9 & $3,228.8$ \\
974.6 & $6,514.3$ & -249.7 & $2,440.8$ \\
-- & -- & 39.1 & 399.0 \\
$8,673.5$ & $46,939.4$ & $-4,080.6$ & $5,300.2$ \\
-- & -- & 66.6 & 182.5 \\
$25,156.5$ & $36,689.2$ & $3,096.8$ & $58,500.0$ \\
858.4 & $6,499.2$ & -425.3 & $2,780.7$ \\
$11,082.0$ & $22,581.0$ & 813.7 & $22,766.2$ \\
$-2,825.7$ & $1,282.7$ & -794.4 & 212.3 \\
-- & -- & 0.8 & 17.9 \\
-- & -- & -8.6 & 38.2 \\
-- & -- & -9.4 & 44.5 \\
$2,361.0$ & $3,061.2$ & 317.3 & $1,152.7$ \\
$2,819.1$ & $4,827.9$ & 341.9 & $1,995.8$ \\
-- & -- & -5.8 & 6.6 \\
$1,583.9$ & $6,290.5$ & -42.8 & $3,100.8$ \\
$7,536.4$ & $14,121.6$ & 156.9 & $6,715.0$ \\
$2,036.6$ & $2,767.3$ & 228.4 & 945.0 \\
-- & -- & -3.5 & 4.0 \\
-- & -- & -1.8 & 3.1 \\
-- & -- & 3.4 & 139.5 \\
-- & -- & 72.6 & $2,744.0$ \\
-- & -- & -397.3 & 909.1 \\
$17,314.3$ & $8,053.1$ & 719.2 & $7,071.9$ \\
-- & -- & 8.0 & 171.5 \\
-- & -- & -59.3 & 144.0 \\
-- & -- & 20.7 & 160 \\
& & & \\
\hline
\end{tabular}




\begin{tabular}{|c|c|c|c|c|c|c|c|c|c|c|c|c|c|c|c|c|c|c|c|}
\hline ISE30 & ISE30 & ISE50 & ISE30 & ISE30 & ISE30 & ISE30 & ISE50 & ISE30 & ISE50 & ISE50 & ISE30 & ISE30 & ISE30 & IHLAS & 13 & $4,447.8$ & $4,338.8$ & -939.7 & $1,580.8$ \\
\hline -- & -- & -- & -- & -- & -- & -- & -- & -- & -- & ISE100 & ISE100 & ISE100 & -- & ISYHO & 13 & -- & -- & -- & -- \\
\hline ISE30 & ISE30 & ISE30 & ISE30 & ISE30 & ISE30 & ISE30 & ISE30 & ISE30 & ISE30 & ISE30 & ISE30 & ISE30 & ISE30 & KCHOL & 13 & -- & -- & $1,980.5$ & $6,424.2$ \\
\hline-- & -- & -- & -- & -- & -- & -- & -- & -- & -- & ISE100 & ISE50 & ISE30 & ISE30 & METRO & 13 & -- & -- & -- & -- \\
\hline ISE50 & ISE50 & ISE50 & ISE50 & ISE50 & ISE50 & ISE50 & ISE50 & ISE50 & ISE50 & ISE50 & ISE100 & ISE100 & ISE50 & NTHOL & 13 & -- & -- & -29.3 & 179.3 \\
\hline ISE30 & ISE30 & ISE30 & ISE30 & ISE30 & ISE30 & ISE30 & ISE30 & ISE30 & ISE30 & ISE30 & ISE30 & ISE30 & ISE30 & SAHOL & 13 & -- & -- & 909.6 & $7,866.0$ \\
\hline ISE30 & ISE30 & ISE30 & ISE30 & ISE30 & ISE30 & ISE30 & ISE30 & ISE30 & ISE30 & ISE30 & ISE30 & ISE30 & ISE30 & SISE & 13 & -- & -- & 131.6 & $1,386.0$ \\
\hline-- & -- & -- & -- & -- & -- & -- & ISE30 & ISE30 & ISE30 & ISE30 & ISE30 & ISE50 & ISE30 & TAVHL & 13 & -- & -- & 0.9 & $1,482.1$ \\
\hline-- & -- & -- & -- & -- & -- & -- & -- & ISE30 & ISE30 & ISE30 & ISE30 & ISE30 & ISE50 & TKFEN & 13 & -- & -- & -19.6 & $1,309.8$ \\
\hline ISE100 & -- & ISE50 & ISE50 & -- & ISE100 & ISE100 & ISE100 & -- & -- & -- & -- & -- & -- & UCAK & 13 & -- & -- & 15.3 & 51.3 \\
\hline ISE50 & ISE50 & ISE50 & ISE50 & ISE50 & ISE30 & ISE100 & ISE100 & ISE100 & ISE100 & -- & -- & -- & ISE50 & YAZIC & 13 & -- & -- & 143.3 & 1080.0 \\
\hline ISE30 & ISE30 & ISE50 & ISE50 & ISE100 & ISE50 & ISE100 & -- & ISE100 & -- & -- & -- & -- & ISE30 & ALCTL & 14 & 715.0 & $3,347.4$ & 158.8 & 685.0 \\
\hline-- & -- & -- & -- & -- & -- & ISE100 & ISE50 & ISE100 & ISE100 & -- & ISE30 & -- & ISE30 & ANELT & 14 & 709.5 & 889.3 & 79.1 & 646.8 \\
\hline-- & ISE100 & ISE100 & -- & -- & ISE100 & -- & ISE50 & -- & -- & ISE50 & ISE100 & ISE30 & -- & ARENA & 14 & 425.6 & $6,437.9$ & 20.8 & 350.4 \\
\hline ISE100 & -- & ISE100 & -- & -- & ISE50 & ISE100 & -- & ISE100 & ISE30 & -- & -- & -- & -- & LINK & 14 & -- & -- & -0.2 & 10.1 \\
\hline-- & -- & -- & ISE50 & ISE100 & -- & ISE50 & ISE100 & -- & -- & -- & -- & -- & -- & LOGO & 14 & -- & -- & -2.9 & 39.0 \\
\hline ISE30 & ISE30 & ISE30 & ISE30 & ISE30 & ISE50 & ISE100 & ISE100 & ISE100 & -- & ISE100 & ISE50 & ISE30 & ISE50 & NETAS & 14 & $2,350.0$ & $1,827.9$ & 122.9 & $1,543.8$ \\
\hline ISE30 & ISE30 & ISE30 & ISE30 & ISE30 & ISE30 & ISE50 & ISE30 & ISE30 & ISE30 & ISE30 & ISE50 & ISE100 & -- & AKGRT & 15 & -- & -- & 41.4 & $1,236.2$ \\
\hline ISE100 & ISE100 & ISE100 & ISE100 & ISE100 & ISE100 & ISE100 & ISE100 & ISE100 & ISE100 & ISE50 & -- & ISE30 & ISE100 & ANHYT & 15 & -- & -- & 67.5 & 612.5 \\
\hline ISE100 & ISE50 & ISE100 & ISE100 & ISE50 & ISE50 & ISE50 & ISE50 & ISE50 & ISE30 & ISE50 & ISE50 & ISE100 & ISE100 & ANSGR & 15 & -- & -- & 118.4 & 451.5 \\
\hline-- & ISE100 & ISE100 & ISE100 & ISE100 & -- & -- & -- & ISE100 & ISE100 & -- & -- & -- & -- & GUSGR & 15 & -- & -- & 10.6 & 258.0 \\
\hline-- & -- & -- & ISE100 & ISE100 & -- & -- & ISE100 & ISE100 & ISE100 & ISE50 & ISE100 & -- & -- & YKSGR & 15 & -- & -- & 61.8 & 644.0 \\
\hline ISE100 & ISE50 & ISE50 & -- & ISE50 & ISE50 & ISE50 & ISE50 & ISE50 & ISE50 & ISE50 & ISE100 & ISE100 & ISE100 & PRKME & 16 & -- & -- & 81.9 & 410.8 \\
\hline -- & -- & -- & -- & -- & -- & -- & -- & -- & ISE50 & ISE30 & ISE30 & ISE30 & ISE30 & KOZAA & 16 & -- & -- & 9.4 & 558.8 \\
\hline-- & -- & -- & -- & -- & -- & -- & -- & -- & -- & ISE30 & ISE30 & ISE30 & ISE30 & KOZAL & 16 & -- & -- & -- & -- \\
\hline ISE30 & ISE100 & ISE100 & ISE100 & -- & -- & ISE100 & ISE100 & ISE100 & ISE100 & ISE100 & ISE50 & -- & ISE100 & ADANA & 17 & $5177.9^{*}$ & $3009.9^{*}$ & $1072.3^{*}$ & $5017.8^{*}$ \\
\hline ISE100 & ISE100 & -- & -- & ISE30 & -- & -- & ISE50 & -- & -- & -- & -- & -- & -- & ADBGR & 17 & $5177.9^{*}$ & $3009.9 *$ & $1072.3^{*}$ & $5017.8^{*}$ \\
\hline-- & ISE100 & -- & ISE100 & ISE100 & ISE100 & ISE100 & -- & -- & -- & ISE100 & ISE100 & ISE100 & -- & ADNAC & 17 & $5177.9^{*}$ & $3009.9 *$ & $1072.3^{*}$ & $5017.8^{*}$ \\
\hline ISE50 & -- & ISE30 & -- & -- & -- & -- & -- & ISE100 & ISE100 & ISE50 & ISE100 & ISE50 & ISE50 & AFYON & 17 & -- & -- & -0.3 & 94.2 \\
\hline ISE30 & ISE50 & ISE50 & ISE100 & ISE100 & ISE100 & ISE30 & ISE50 & ISE30 & ISE100 & ISE100 & ISE100 & ISE100 & -- & AKCNS & 17 & -- & -- & 92.7 & 666.2 \\
\hline ISE100 & ISE30 & ISE30 & ISE50 & ISE50 & ISE100 & ISE100 & ISE100 & -- & ISE50 & -- & ISE50 & -- & ISE100 & ANACM & 17 & $8,615.7$ & $10,814.4$ & $2,566.9$ & $5,332.2$ \\
\hline-- & ISE100 & ISE100 & ISE100 & ISE50 & ISE100 & ISE100 & -- & ISE30 & -- & ISE30 & -- & -- & -- & BOLUC & 17 & $2,059.1$ & $1,676.0$ & 392.8 & $1,812.8$ \\
\hline ISE50 & ISE100 | & ISE100 & ISE100 & ISE100 & ISE100 & ISE100 & ISE100 & ISE100 & ISE100 & -- & -- & -- & ISE100 & CIMSA & 17 & $7,589.1$ & $6,104.7$ & 761.5 & $5,916.7$ \\
\hline
\end{tabular}




\begin{tabular}{|c|c|c|c|c|c|c|c|c|c|c|c|c|c|c|c|c|c|c|c|}
\hline ISE100 & ISE100 & ISE100 & ISE100 & ISE100 & ISE100 & ISE100 & ISE100 & ISE100 & -- & -- & -- & -- & -- & ECYAP & 17 & $1,123.0$ & $3,826.6$ & -854.2 & $1,760.0$ \\
\hline-- & -- & -- & ISE100 & ISE100 & -- & -- & ISE100 & ISE100 & ISE100 & ISE100 & ISE100 & -- & -- & EGSER & 17 & $1,206.8$ & $1,528.7$ & -153.3 & 592.5 \\
\hline ISE100 & ISE100 & -- & -- & -- & -- & ISE30 & ISE100 & -- & ISE100 & ISE100 & ISE100 & ISE100 & ISE100 & GOLTS & 17 & $2,839.3$ & $1,701.5$ & 121.2 & $2,808.0$ \\
\hline-- & -- & ISE30 & -- & -- & -- & ISE50 & ISE50 & -- & -- & ISE100 & ISE50 & ISE50 & ISE50 & KONYA & 17 & $3,249.5$ & $1,879.7$ & 352.4 & $2,229.6$ \\
\hline ISE100 & -- & ISE100 & -- & -- & -- & -- & -- & ISE30 & -- & ISE30 & -- & -- & -- & KUTPO & 17 & 866.9 & $1,532.2$ & 14.3 & 587.3 \\
\hline ISE50 & ISE50 & ISE100 & ISE100 & ISE100 & ISE100 & ISE100 & ISE50 & -- & ISE100 & -- & -- & ISE100 & -- & MRDIN & 17 & $2,205.4$ & $2,081.7$ & 684.0 & $4,616.3$ \\
\hline ISE50 & ISE30 & ISE30 & ISE30 & ISE30 & ISE50 & ISE50 & ISE50 & ISE50 & ISE50 & ISE100 & ISE100 & ISE50 & ISE50 & TRKCM & 17 & $12,792.4$ & $9,762.5$ & $1,211.7$ & $6,855.2$ \\
\hline ISE50 & ISE50 & -- & ISE100 & ISE100 & -- & -- & ISE50 & -- & -- & -- & -- & -- & -- & ADEL & 18 & 494.1 & 782.4 & 137.2 & 397.7 \\
\hline-- & -- & -- & -- & -- & ISE50 & ISE100 & ISE30 & ISE100 & -- & ISE50 & ISE100 & ISE100 & ISE100 & SERVE & 18 & -- & -- & -1.5 & 9.0 \\
\hline ISE100 & -- & -- & ISE100 & ISE100 & ISE100 & ISE100 & ISE30 & -- & ISE100 & ISE100 & ISE100 & -- & -- & ALKA & 19 & -- & -- & 10.1 & 75.0 \\
\hline-- & -- & -- & -- & -- & ISE100 & ISE100 & ISE100 & ISE100 & ISE50 & ISE100 & ISE50 & -- & -- & DGZTE & 19 & $2,410.5$ & $3,413.5$ & -7.5 & $1,911.0$ \\
\hline-- & -- & ISE30 & ISE100 & -- & ISE50 & ISE100 & ISE50 & -- & -- & -- & -- & ISE100 & -- & DOBUR & 19 & 389.8 & 863.6 & 67.2 & 435.1 \\
\hline ISE30 & ISE30 & ISE30 & ISE30 & ISE30 & ISE30 & ISE30 & ISE30 & ISE30 & ISE50 & ISE50 & ISE50 & ISE100 & ISE100 & HURGZ & 19 & $8,862.0$ & $9,984.5$ & -380.9 & $4,554.0$ \\
\hline ISE100 & ISE50 & -- & -- & -- & ISE50 & ISE50 & ISE50 & ISE100 & ISE30 & ISE100 & ISE50 & ISE50 & ISE30 & KARTN & 19 & $1,527.1$ & $1,346.0$ & 146.4 & $1,773.1$ \\
\hline-- & -- & -- & -- & ISE100 & ISE50 & -- & ISE100 & ISE100 & -- & ISE50 & ISE100 & ISE100 & ISE100 & TIRE & 19 & 147.3 & $2,521.6$ & -636.0 & $2,680.0$ \\
\hline-- & -- & ISE100 & ISE30 & ISE100 & ISE100 & ISE100 & ISE100 & ISE100 & ISE100 & -- & -- & -- & -- & AGYO & 20 & -- & -- & 15.6 & 99.1 \\
\hline ISE30 & ISE30 & ISE30 & ISE50 & ISE30 & ISE30 & ISE30 & ISE30 & ISE30 & ISE30 & ISE50 & ISE50 & ISE100 & ISE100 & ISGYO & 20 & -- & -- & 50.8 & 481.5 \\
\hline-- & ISE50 & ISE100 & -- & ISE30 & -- & ISE100 & ISE100 & -- & -- & -- & -- & ISE100 & -- & NUGYO & 20 & -- & -- & 9.0 & 28.0 \\
\hline-- & -- & -- & -- & -- & -- & -- & -- & ISE30 & ISE100 & ISE100 & ISE100 & ISE30 & -- & PEGYO & 20 & -- & -- & -5.9 & 57.6 \\
\hline-- & -- & -- & -- & -- & -- & -- & -- & ISE100 & ISE50 & ISE50 & ISE30 & ISE30 & ISE50 & SNGYO & 20 & -- & -- & 23.3 & 531.4 \\
\hline ISE50 & ISE100 & ISE100 & ISE100 & ISE100 & ISE100 & ISE100 & -- & -- & -- & -- & -- & -- & -- & YKGYO & 20 & -- & -- & -15.5 & 56.0 \\
\hline-- & -- & -- & -- & -- & -- & -- & -- & -- & ISE100 & ISE50 & ISE100 & ISE100 & -- & MARTI & 21 & -- & -- & -0.2 & 59.2 \\
\hline-- & -- & ISE30 & -- & ISE30 & ISE100 & -- & -- & -- & -- & ISE50 & -- & -- & -- & METUR & 21 & -- & -- & -9.1 & 12.2 \\
\hline ISE100 & ISE100 & ISE30 & ISE100 & ISE100 & ISE50 & ISE100 & ISE100 & ISE100 & ISE100 & ISE100 & ISE100 & ISE100 & ISE100 & NTTUR & 21 & -- & -- & -40.0 & 73.8 \\
\hline-- & -- & -- & -- & -- & ISE100 & ISE100 & ISE100 & ISE100 & -- & -- & ISE100 & ISE100 & -- & TEKTU & 21 & -- & -- & -1.9 & 81.5 \\
\hline-- & ISE30 & ISE30 & ISE30 & ISE30 & ISE30 & ISE30 & ISE30 & ISE30 & ISE30 & ISE30 & ISE30 & ISE30 & ISE30 & TCELL & 22 & $81,720.6$ & $88,446.4$ & $23,128.0$ & $180,400.0$ \\
\hline-- & -- & -- & -- & -- & -- & -- & -- & ISE30 & ISE30 & ISE30 & ISE30 & ISE30 & ISE30 & TTKOM & 22 & $51,136.1$ & $101,949.5$ & $17,522.1$ & $152,600.0$ \\
\hline-- & -- & -- & ISE100 & ISE30 & ISE100 & ISE100 & -- & -- & -- & ISE50 & ISE50 & ISE30 & -- & ARSAN & 23 & 416.5 & $1,235.9$ & 73.8 & 483.8 \\
\hline-- & -- & ISE100 & ISE100 & -- & -- & -- & ISE100 & -- & ISE30 & -- & -- & ISE100 & -- & ATEKS & 23 & $1,013.1$ & $1,350.2$ & -170.5 & 796.3 \\
\hline ISE100 & ISE100 & ISE100 & ISE100 & ISE100 & ISE30 & ISE50 & ISE100 & ISE100 & ISE100 & -- & -- & -- & ISE100 & BOSSA & 23 & $2,911.8$ & $2,710.8$ & 261.4 & $3,412.8$ \\
\hline-- & -- & -- & -- & ISE30 & -- & -- & ISE100 & -- & -- & ISE50 & ISE100 & -- & ISE100 & DESA & 23 & 622.1 & $1,025.1$ & -35.4 & 285.5 \\
\hline ISE30 & -- & ISE100 & ISE50 & ISE100 & ISE100 & -- & -- & -- & -- & ISE100 & -- & -- & ISE50 & GEDIZ & 23 & -- & -- & -2.7 & 5.5 \\
\hline ISE30 & ISE100 & ISE100 & ISE100 & ISE100 & ISE100 & -- & ISE100 & -- & -- & -- & ISE100 & -- & ISE100 & KORDS & 23 & $7,828.6$ & $11,400.1$ & 409.9 & $3,968.4$ \\
\hline
\end{tabular}




\begin{tabular}{|c|c|c|c|c|c|c|c|c|c|c|c|c|c|c|c|c|c|c|c|}
\hline-- & -- & ISE100 & ISE30 & ISE30 & -- & -- & ISE100 & -- & -- & ISE50 & -- & -- & ISE100 & | KRTEK & 23 & 730.3 & 960.0 & -35.4 & 200.1 \\
\hline-- & ISE100 & -- & ISE100 & -- & -- & ISE100 & -- & -- & -- & -- & ISE30 & -- & ISE100 & LUKSK & 23 & - & -- & -0.7 & 18.5 \\
\hline ISE100 & ISE30 & -- & -- & -- & ISE50 & -- & -- & -- & ISE30 & -- & -- & -- & -- & MEMSA & 23 & -- & -- & -48.0 & 42.3 \\
\hline-- & ISE100 & ISE50 & ISE30 & ISE50 & ISE100 & ISE100 & ISE100 & ISE100 & -- & -- & ISE30 & ISE100 & ISE100 & MNDRS & 23 & $2,125.9$ & $2,673.3$ & -112.7 & 680.8 \\
\hline ISE100 & ISE100 & ISE100 & ISE100 & -- & -- & ISE100 & ISE100 & ISE100 & ISE100 & ISE100 & -- & -- & ISE100 & CLEBI & 24 & $1,303.3$ & $3,019.7$ & 350.4 & $2,296.4$ \\
\hline ISE30 & ISE50 & ISE100 & ISE100 & ISE100 & ISE30 & ISE30 & ISE30 & ISE30 & ISE30 & ISE30 & ISE30 & ISE30 & ISE30 & THYAO & 24 & $29,865.9$ & $61,231.7$ & $11,342.3$ & $16,187.5$ \\
\hline-- & -- & -- & -- & -- & ISE50 & ISE30 & ISE30 & ISE50 & ISE100 & ISE100 & ISE100 & ISE100 & ISE50 & DOAS & 25 & $3,518.0$ & $21,441.4$ & $-1,097.5$ & $4,092.0$ \\
\hline-- & ISE50 & ISE50 & ISE50 & ISE50 & ISE100 & -- & -- & -- & -- & -- & -- & -- & -- & SANKO & 25 & -- & -- & 7.2 & 97.8 \\
\hline-- & -- & -- & -- & -- & -- & -- & ISE50 & ISE50 & ISE50 & ISE50 & -- & -- & -- & SELEC & 25 & -- & -- & 171.8 & $1,128.1$ \\
\hline ISE100 & -- & -- & ISE30 & -- & ISE30 & -- & -- & -- & ISE100 & -- & -- & ISE100 & ISE30 & GENTS & 26 & -- & -- & 6.0 & 60.3 \\
\hline
\end{tabular}

Notes: The market values, as of June 2009, are calculated on basis of closing prices on the last trading day of the month. Total Assets, Net Sales, and Net Profits are for are for 2008. Net profits are the sum net profits in the last four quarters. All values are in millions of Turkish Lira (TL). The values with * are the sum of values for companies of the same origin. 